\title{
Localization of the Carnation Italian ringspot virus replication protein p36 to the mitochondrial outer membrane is mediated by an internal targeting signal and the TOM complex Yeen Ting Hwang ${ }^{\dagger}$, Andrew W McCartney ${ }^{\dagger 1,2}$, Satinder K Gidda ${ }^{1}$ and Robert T Mullen*1
}

Address: ${ }^{1}$ Department of Molecular and Cellular Biology, University of Guelph, Guelph, Ontario, N1G 2W1, Canada and 2JD Irving, Limited, Woodlands Division, 1350 Regent Street, Fredericton, New Brunswick, E3C 2G6, Canada

Email: Yeen Ting Hwang - hwangy@uoguelph.ca; Andrew W McCartney - McCartney.Andrew@jdirving.com;

Satinder K Gidda - sgidda@uoguelph.ca; Robert T Mullen* - rtmullen@uoguelph.ca

* Corresponding author †Equal contributors

Published: 23 September 2008

BMC Cell Biology 2008, 9:54 doi:10.1 186/1471-2121-9-54

This article is available from: http://www.biomedcentral.com/I47I-2I II/9/54

(C) 2008 Hwang et al; licensee BioMed Central Ltd.

This is an Open Access article distributed under the terms of the Creative Commons Attribution License (http://creativecommons.org/licenses/by/2.0), which permits unrestricted use, distribution, and reproduction in any medium, provided the original work is properly cited.

\begin{abstract}
Background: Carnation Italian ringspot virus (CIRV) is a positive-strand RNA virus that causes massive structural alterations of mitochondria in infected host cells, the most conspicuous being the formation of numerous internal vesicles/spherules that are derived from the mitochondrial outer membrane and serve as the sites for viral RNA replication. While the membrane-bound components of the CIRV replication complex, including a 36-kD RNA-binding protein ( $\mathrm{p} 36$ ), are known to be essential for these changes in mitochondrial morphology and are relatively well characterized in terms of their roles in nascent viral RNA synthesis, how these proteins are specifically targeted and inserted into mitochondria is poorly defined.
\end{abstract}

Results: Here we report on the molecular signal responsible for sorting p36 to the mitochondrial outer membrane. Using a combination of gain-of-function assays with portions of $p 36$ fused to reporter proteins and domain-swapping assays with p36 and another closely-related viral RNAbinding protein, $\mathrm{p} 33$, that sorts specifically to the peroxisomal boundary membrane, we show that the mitochondrial targeting information in $\mathrm{p} 36$ resides within its two transmembrane domains (TMDs) and intervening hydrophilic loop sequence. Comprehensive mutational analysis of these regions in $\mathrm{p} 36$ revealed that the primary targeting determinants are the moderate hydrophobicity of both TMDs and the positively-charged face of an amphipathic helix within the intervening loop sequence. We show also using bimolecular fluorescence complementation (BiFC) that p36 interacts with certain components of the translocase complex in the mitochondrial outer membrane (TOM), but not with the sorting and assembly machinery (SAM).

Conclusion: Our results provide insight to how viruses, such as CIRV, exploit specific host-cell protein sorting pathways to facilitate their replication. The characterization of the targeting and insertion of p36 into the mitochondrial outer membrane also sheds light on the mechanisms involved in sorting of host-cell membrane proteins to mitochondria, a process that has been largely unexplored in plants. 


\section{Background}

The hallmark of positive-strand RNA viruses is their ability to recruit distinct host-cell organelle membranes in order to create unique compartments at which viral RNA replication takes place [1-3]. This process is exemplified during tombusvirus infections of plant cells where, depending on the virus and host, peroxisomes or mitochondria undergo a series of remarkable structural rearrangements that ultimately results in their transformation into so-called multivesicular bodies (MVBs) [reviewed in $[4,5]]$. These novel structures form initially by the proliferation and progressive invagination of the organelle's boundary (outer) membrane, resulting in the matrix or intermembrane space containing hundreds of small ( 80-150 nm diameter) vesicles and/or spherules which serve as the sites of viral RNA replication. MVBs often then form one or more large, vesicle/spherule-containing appendages that encircle portions of the neighbouring cytosol, yielding C-shaped or doughnut-shaped structures that frequently coalesce with other MVBs in the infected cell.

While the cytolopathological features of MVB biogenesis have been relatively well studied, many fundamental questions remain about the molecular mechanisms underlying the interaction of viral replication factors with host-cell membranes. For instance, the significance of the diversity of intracellular membranes used by different viruses is unknown. Likewise, the events involved in the specific intracellular targeting and membrane integration/ assembly of the viral replication proteins, as well as the host-cell factors that facilitate these processes and/or mediate membrane remodelling are, in most cases, poorly studied and unclear.

CIRV is a member of the Tombusviridae family of positivestrand RNA plant viruses that include Cymbidium ringspot virus (CymRSV) and the Tomato bushy stunt virus (TBSV) $[6,7]$. Similar to other tombusviruses, the CIRV genome consists of a 4.8-kb linear, monopartite RNA molecule that contains five open reading frames (ORFs) [8], including ORF1 and ORF2, a 36-kD RNA-binding protein (p36) and its translation read-through product, a 95-kD RNAdependent RNA polymerase (p95). Both p36 and p95 are the integral membrane-bound components of the virus' RNA replication complex and are located within the virusinduced vesicles/spherules of the MVB [9-12]. The remaining three ORFs in the CIRV genome encode a 41$\mathrm{kD}$ coat protein, a $22-\mathrm{kD}$ protein required for cell-to-cell movement of the virus, and a $19-\mathrm{kD}$ protein that functions as a suppressor of virus-induced gene silencing [7].

In CIRV-infected cells, MVBs are derived from mitochondria [13] and the principal viral component involved in this process appears to be p36. For instance, analysis of full-length hybrid infectious clones of CIRV and CymRSV, which, unlike CIRV, recruits peroxisomes for its viral RNA replication, revealed that both of their ORF1s, namely p36 and the CymRSV 33-kD membrane-bound replication protein (p33), contain the determinants for the formation of MVBs derived from mitochondria or peroxisomes, respectively $[14,15]$. p36 expressed alone in either tobacco mesophyll or in yeast (Saccharomyces cerevisiae) cells is also sufficient to target the green fluorescent protein (GFP) to mitochondria and while these organelles are not entirely transformed into MVBs, they displayed dramatic alterations in their distribution and morphology, including proliferation of their outer membranes [16,17]. Interestingly, results from previous studies of p36 suggest also that its sorting to mitochondrial outer membranes is atypical since it does not appear to rely on mitochondrialsurface proteinaceous receptors nor a targeting/insertion signal similar to those typically found in most host-cell mitochondrial membrane- or matrix-localized proteins [18]. The nature of the sorting pathway for $\mathrm{p} 36$, instead, is considered to be complex, consisting of multiple, perhaps novel, targeting/insertion signals and a unique membrane insertion mechanism [18], however, this premise has not been experimentally tested.

Here, we describe the results of a comprehensive study of the molecular signals involved in the mitochondrial targeting of p36. We show using a combination of p36reporter fusion proteins and p36-p33 hybrid proteins, wherein specific regions of $\mathrm{p} 36$ were replaced with those that constitute the peroxisomal targeting information in p33 (and vice versa), that the mitochondrial sorting of p36 is mediated by an internal targeting signal consisting of its two moderately hydrophobic TMDs and a positively-charged face of an amphipathic helix located within the intervening loop sequence. Notably, this targeting signal in p36 resembles the targeting determinants in several authentic mitochondrial outer membrane proteins from evolutionarily diverse organisms. We show also that p36 interacts with certain components of the translocase in the mitochondrial outer membrane (TOM), but not with the sorting and assembly machinery (SAM), in a manner consistent with the insertion of some host-cell mitochondrial outer membrane proteins. The implications of these findings in terms of CIRV's and other positive-strand RNA viruses' strategies to appropriate and subsequently modify mitochondrial sorting pathways to their own advantage are briefly discussed. Also discussed is how these results provide insight to the cellular processes underlying plant mitochondrial outer membrane protein sorting in general. 


\section{Results and discussion p36 expressed transiently in tobacco BY-2 cells is localized to mitochondrial outer membranes}

To begin to decipher the intracellular targeting information within p36, we took advantage of tobacco (Nicotiana tabacum) Bright Yellow-2 (BY-2) suspension-cultured cells as a well-characterized in vivo import system [19-21]. Specifically, BY-2 cells were transiently transformed (via biolistic bombardment) with plasmid DNA encoding p36 fused at either its $\mathrm{N}$ or $\mathrm{C}$ terminus to the myc-epitope recognition motif (-EQKLISEEDL-; [22]) and, then, following a $4 \mathrm{~h}$ incubation period to allow for gene expression and protein sorting, cells were processed for indirect immunofluorescence confocal-laser scanning microscopy (CLSM). As shown in Figure 1, both transiently-expressed myc-p36 and p36-myc localized exclusively to globular structures that were found mostly within the perinuclear region of the cell and contained endogenous $\mathrm{E} 1 \beta$, a protein subunit of the pyruvate dehydrogenase complex located in the mitochondrial matrix [23]. Interestingly, close inspection of these p36-containing globular structures at higher magnification revealed that they actually consisted of numerous torus or donut-shaped structures that contained myc-p36 or p36-myc and that enclosed spherical fluorescent structures containing matrix-localized E1 $\beta$ (refer to arrowheads in Figure 1). These toroidal structures also contained the endogenous mitochondrial outer membrane protein porin [24], as evidenced by the colocalization of p36-myc and porin (Figure 1). Taken together, these results indicate that $\mathrm{p} 36$ sorts to mitochondrial outer membranes in BY-2 cells and that the expression of this viral protein causes mitochondria to coalesce in perinuclear regions, in contrast to mitochondria in non-transformed cells that are distributed throughout the

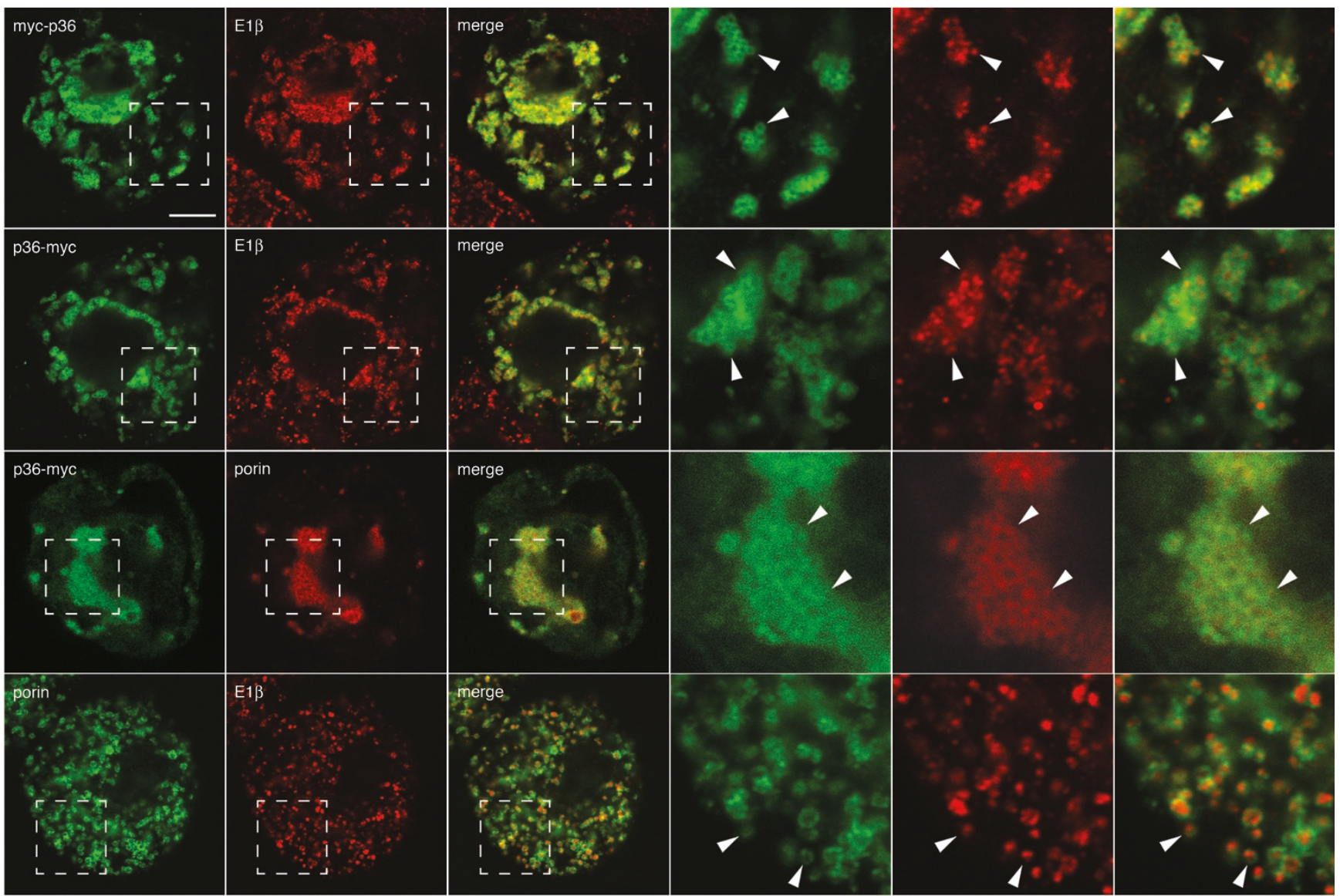

\section{Figure I}

Localization of p36 to the outer mitochondrial membrane in BY-2 cells. Tobacco BY-2 cells were either non-transformed or transformed transiently (via biolistic bombardment) with either myc-p36 or p36-myc and then processed for immunofluorescence CLSM. Hatched boxes represent the portion of the cells shown at higher magnification in the panels to the right. Arrowheads indicate obvious examples of the torus fluorescent structures containing myc-p36 or p 36-myc either delineating the spherical structures containing endogenous mitochondrial matrix-localized EI $\beta$ or colocalizing with the torus structures containing the endogenous mitochondrial outer membrane protein porin. The bottom row of images show representative immunofluorescence staining patterns attributable to endogenous porin and EI $\beta$ in non-transformed cells; arrowheads in the high magnified images indicate obvious examples of porin-containing torus structures (similar to those containing myc-p36 or p36-myc [compare with cells above]) enclosing the EI $\beta$ containing spheres. Bar $=10 \mu \mathrm{m}$. 
cytosol; refer to images of the immunostaining of endogenous mitochondrial porin and $\mathrm{E} 1 \beta$ in the non-transformed cells shown in the bottom row of Figure 1.

While it remains to be determined whether the aggregated mitochondria in p36-transformed cells were modified also in terms of their ultrastructure, this possibility is likely since expression of p36 (e.g., p36-GFP) in various other cell types (e.g., leaf mesophyll protoplasts and yeast cells) led to similar aggregations of mitochondria, as well as a proliferation of their outer membranes [16-18]. Indeed, high-magnified views of myc-p36- or p36-myctransformed BY-2 cells in this study revealed that the immunostaining pattern attributable to endogenous porin in these cells was more diffuse than that observed in non-transformed cells (Figure 1), suggesting that the outer mitochondrial membranes in the former cells were altered in terms of their morphology. The nature of these changes or the mechanism(s) by which p36 participates in this process were not, however, examined further.

The localization of myc-p36 and p36-myc to mitochondria indicates also that appending the myc epitope to the $\mathrm{N}$ or $\mathrm{C}$ terminus of p36 did not disrupt the protein's normal targeting behaviour, since non-tagged (wild-type) p36 colocalized also with endogenous porin in the outer membranes of aggregated mitochondria (refer to Additional file 1A, top row). p36 was immunodetected in these cells using polyclonal antibodies raised against a synthetic peptide corresponding to an amino acid sequence in the C-terminal half of TBSV p33 and p92 replicase proteins (residues 184-203; [25]) and conserved in CIRV p36 and p95 (residues 218-237). However, due to limited availability of this antibody reagent, only myc-tagged versions of p36, primarily p36-myc, were employed in the remainder of the experiments described in this manuscript.

The localization of epitope-tagged and wild-type p36 to mitochondrial outer membranes, and their subsequent effects on mitochondrial morphology and distribution, were similar also to when p36 was co-expressed with its allied replication protein, p95, either together alone (Rep) or together in the context of full-length CIRV, i.e., a CIRV cDNA positioned within a plant expression plasmid (Additional file 1A). Confirmation of the infectivity of this CIRV cDNA was that Chenopodium quinoa leaves 7 to 10 days after rub-inoculation displayed local lesions (Additional file 1B) that resembled the disease symptoms reported for leaves infected with native CIRV RNA [4]. Moreover, electron microscopic analyses of these CIRV cDNA-inoculated leaf samples revealed the presence of mitochondrial-derived MVBs that were not observed in cells from mock-transformed leaves (Additional file 1C). The results for the mitochondrial localization of p36 expressed in the context of full-length CIRV (or Rep) are important because they indicate that, compared to the expression of p36 alone (either wild-type or epitope tagged), the viral protein behaves in a similar manner in terms of its intracellular localization. Thus, we deemed it appropriate to study the mitochondrial targeting information of p36 when expressed on its own.

\section{p36 is orientated in mitochondrial outer membranes in an $\mathrm{N}_{\text {out }}-\mathrm{C}_{\text {out }}$ topology}

The topological orientation of p36 in mitochondrial outer membranes was assessed using a differential detergent permeabilization assay [26]. Specifically, BY-2 cells were transformed transiently with $\mathrm{N}$ - or C-terminal myc-tagged versions of p36 and then fixed and incubated either with triton X-100, which perforates all cellular membranes, or with digitonin, which perforates only the plasma membrane.

As shown in Figure 2 (top row), control experiments with myc-p36-transformed cells verified that permeabilization with triton X-100 allowed for the immunodetection (via
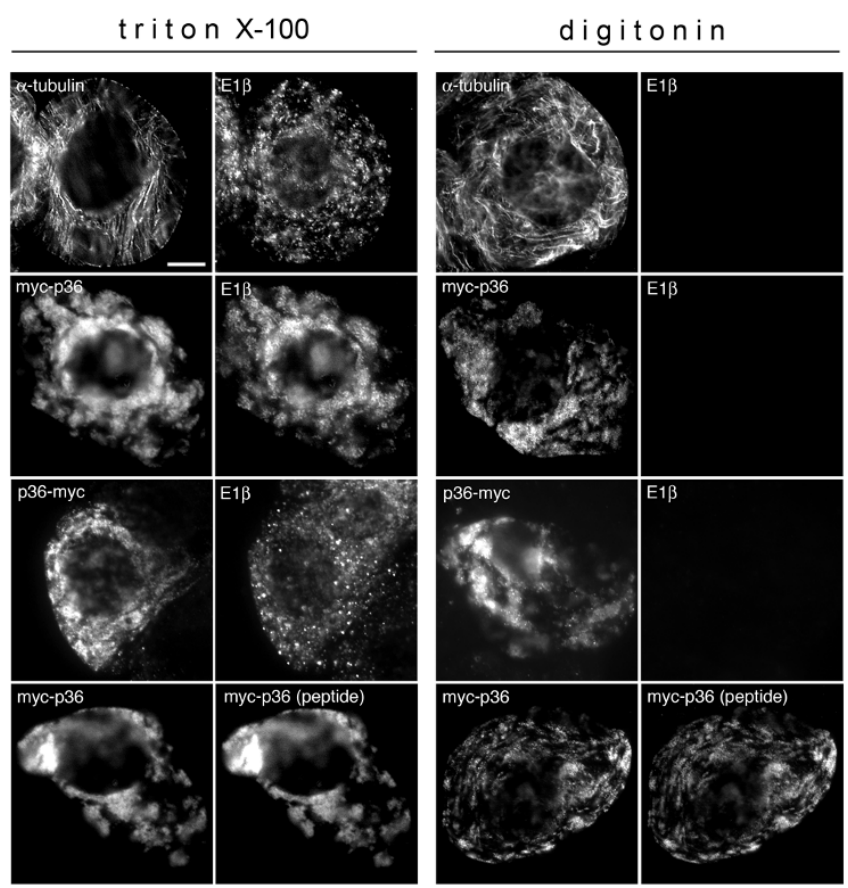

Figure 2

Topological orientation of p36 in differentially permeabilized BY-2 cells. BY-2 cells were either non-transformed or transformed transiently (via biolistic bombardment) with myc-p36 or p36-myc, fixed, and then permeabilized with either triton X-100 (which permeabilizes both the plasma membrane and organellar membranes) or digitonin (which permeabilizes only the plasma membrane). Permeabilized cells were then processed for (immuno)epifluorescence microscopy using antibodies raised against (as indicated by the labelling at the top left of each micrograph) either cytosolic $\alpha$-tubulin, mitochondrial matrix-localized EI $\beta$, the myc epitope and/or the $\mathrm{p} 36 \mathrm{C}$-terminal peptide sequence (amino acids 218 237) located downstream of the protein's second (of two) predicted TMDs. Bar $=10 \mu \mathrm{m}$. 
epifluorescence microscopy) of endogenous proteins within the cytosol (i.e., $\alpha$-tubulin) and within subcellular compartments (i.e., E1 $\beta$ within the mitochondrial matrix), whereas permeabilization with digitonin allowed for the immunodetection of only cytosolic proteins (i.e., $\alpha$-tubulin, but not E1 $\beta$ ). Figure 2 shows also that when myc-p36- or p36-myc-transformed cells were permeabilized with either triton X-100 or digitonin both expressed proteins were immunodetected, whereas endogenous E1 $\beta$ was only immunodetected in the corresponding triton-X100-permeabilized cells. Likewise, myc-p36 was immunodetected in both triton X-100- and digitonin-permeabilized cells that were incubated with antibodies specific for myc or the p36 C-terminal peptide mentioned above, i.e., amino acid residues 218-237 located downstream of the second (of two) predicted TMDs in $\mathrm{p} 36$.

Overall, these data are in agreement with the previously proposed model for the membrane topology of p36 based on the hydropathy profile of the protein's primary amino acid sequence [15] and protease resistance analyses of p36 in either CIRV-infected plants or isolated mitochondria [18]. In this model, p36 is predicted to be an integral membrane protein that contains two TMDs (residues 102-119 and 166-188), an intervening loop region (residues 120-165) orientated towards the mitochondrial intermembrane space, and $\mathrm{N}$ - and $\mathrm{C}$ terminal portions of the protein (residues 1-101 and 189-296) that face the cytosol. Unfortunately, our efforts to confirm the inward orientation of the intervening loop sequence in p36 were unsuccessful, because addition of the myc-epitope sequence to this portion of the protein caused the resulting mutant to be mislocalized from mitochondria to the cytosol in transformed cells (data not shown), a result that is likely due to the fact that, as discussed below, the loop sequence of p36 contains essential mitochondrial targeting information that was disrupted by the addition of the myc-epitope motif.

\section{An internal domain of $p 36$ composed of two TMDs and an intervening loop sequence functions as a mitochondrial targeting signal}

While previous studies using chimeras of CIRV p36 and CymRSV p33, expressed either in the context of the fulllength virus or alone, revealed that the $\mathrm{N}$ terminal half of each protein is responsible for its sorting to mitochondria and peroxisomes, respectively $[14,15]$, results from subsequent mutational analyses of $\mathrm{p} 36$ expressed alone provided only limited insight to the precise nature the protein's mitochondrial targeting information [18]. For instance, based on the targeting results of various p36 deletion mutants, Weber-Lotfi et al. [18] concluded that the mitochondrial sorting of $\mathrm{p} 36$ is mediated by multiple determinants located within a relatively large portion of the protein's N-terminal half, i.e., residues 84-196 which includes both of the protein's TMDs and their flanking regions, and that together these determinants might function cooperatively as a so-called signal loop-anchor type mitochondrial targeting sequence. These authors also speculated that this putative signal loop-anchor targeting sequence for $\mathrm{p} 36$ was unique because, rather than being comprised of non-continuous structural elements and/or three-dimensional folding features, such as those that typically constitute the targeting determinants in host-cell multi-spanning mitochondrial outer membrane proteins with $\beta$-barrel structures, the mitochondrial targeting determinants in p36 (a non- $\beta$-barrel protein) were part of a linear stretch of the protein. The physicochemical properties of these potentially novel targeting determinants in p36 were not, however, defined. Thus, to better understand the mitochondrial targeting information in p36 we carried out a comprehensive mutational analysis of the protein, employing initially both gain-of-function targeting assays with different portions of p36 fused to a reporter protein (Figure 3 ) and domain-swapping assays with p36 and p33 (Figure 4).

As shown in Figure 3A, gain-of-function targeting experiments were carried out using a series of fusion proteins that consisted of p36, or portions thereof, appended to the bacterial passenger protein chloramphenicol acetyltransferase (CAT) and that were expressed transiently in BY-2 cells. The representative micrographs presented in Figure 3B show that while CAT expressed alone accumulated throughout the cytosol, p36-CAT, consisting of fulllength p36 fused to the $\mathrm{N}$ terminus of CAT, localized exclusively to aggregated mitochondria. These latter data are consistent with the localization of myc-tagged and wild-type p36 to (aggregated) mitochondria in BY-2 cells (refer to Figure 1 and Additional file 1), as well as p36 fused to GFP and expressed transiently (via agrobacterium infiltration) in tobacco leaf mesophyll cells $[17,18]$, and indicate that the CAT moiety used here as a reporter passenger protein does not alter the sorting behaviour of $\mathrm{p} 36$.

Similar to p36-CAT, p36 1-190-CAT, containing residues $1-190$ of p36 including the protein's N-terminal hydrophilic domain, TMDs 1 and 2, and the intervening loop sequence appended to CAT, localized to (aggregated) mitochondria (Figure $3 \mathrm{~B}$ ), confirming also the results presented previously by Weber-Lotfi et al. [18] that the $\mathrm{N}$-terminal half of the protein contains its mitochondrial targeting information. By contrast, p36 1-120-CAT, which includes only the $\mathrm{N}$-terminal hydrophilic domain and TMD1 of p36, accumulated in the cytosol. Notably, the mitochondria in these p36 1-120-CAT-transformed cells, similar to mitochondria in cells transformed with CAT alone, were not altered in terms of their morphology and/or distribution (compare endogenous E1 $\beta$ immunostaining in p36 1-120-CAT-and CAT-transformed cells; Fig- 
A

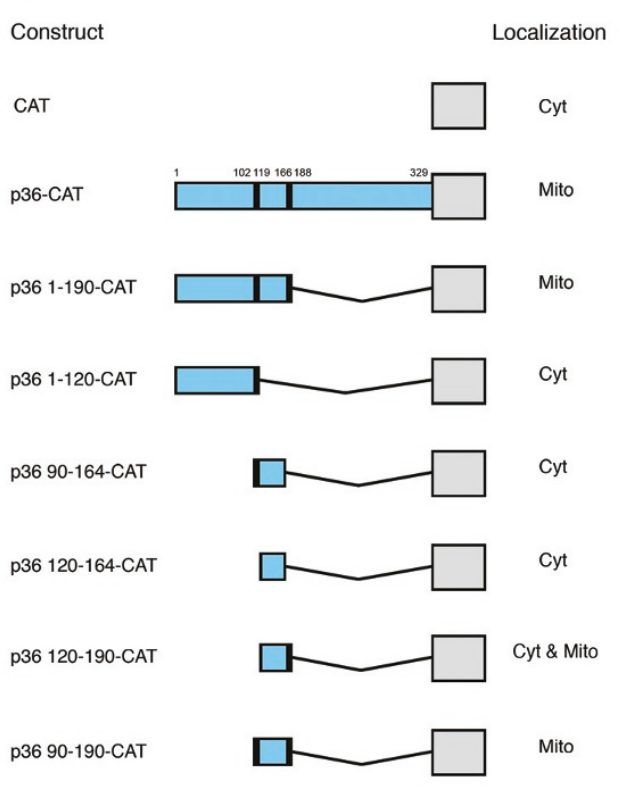

B

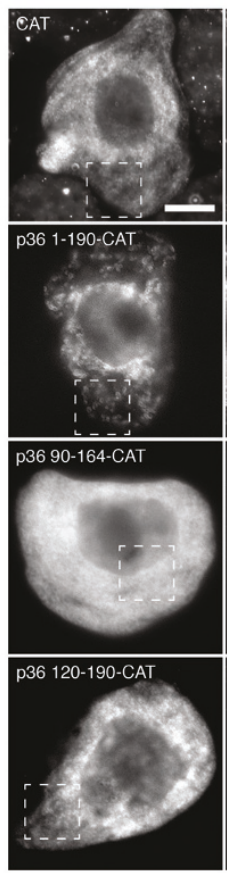

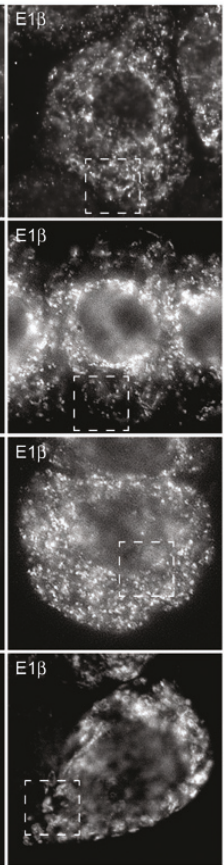

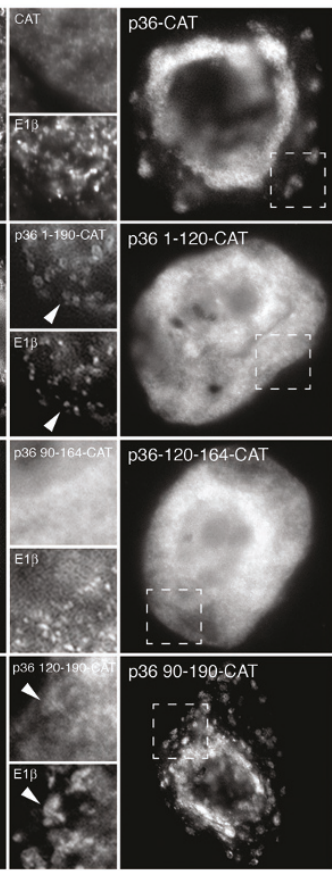

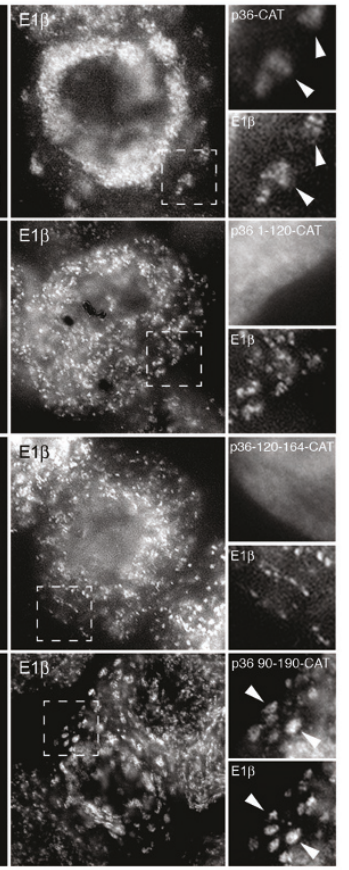

Figure 3

Localization of p36-CAT fusion proteins in BY-2 cells. (A) Schematic illustrations of CAT and various p36-CAT fusion proteins and their corresponding subcellular localizations in transformed (via biolistic bombardment) BY-2 cells. The numbers in the name of each fusion construct denote the specific amino acid residues from $\mathrm{p} 36$ that were fused to the $\mathrm{N}$ terminus of CAT. Portions of the p36 ORF are colored blue or black, the latter denoting the two putative TMDs in $\mathrm{P} 36$ and the numbers shown above P36-CAT include the position of each TMD's left and right amino acid border. Grey boxes denote CAT. Mito, mitochondria; Cyt, cytosol. (B) Representative (immuno)epifluorescence micrographs illustrating the localizations of the various constructs shown in (A). Each micrograph is labelled at the top left with the name of the transiently-expressed fusion protein or the endogenous mitochondrial marker protein, EI $\beta$. Hatched boxes represent the portion of the cells shown at higher magnification in the panels to the right. Arrowheads indicate obvious colocalizations. Bar $=10 \mu \mathrm{m}$.

ure $3 \mathrm{~B}$ ), and reinforcing the notion that this fusion protein was not targeted to mitochondria.

Other p36-CAT fusion proteins comprised of smaller portions of the p36 N-terminal half also did not target to mitochondria. That is, both p36 90-164-CAT and p36 120-164-CAT, consisting of TMD1 and the intervening loop sequence and the intervening loop sequence alone, respectively, localized to the cytosol (Figure $3 \mathrm{~B}$ ). On the other hand, both p36 120-190-CAT and p36 90-190-CAT localized to (aggregated) mitochondria, albeit the former fusion protein only did so in a relatively inefficient manner since it accumulated also in the cytosol (Figure 3B). Based on the results presented here (Figure 3), p36 90190-CAT contains the minimally sufficient portion of the protein capable of efficiently targeting CAT to mitochondria and, similar to wild-type p36, is localized to the outer membranes of mitochondria in an $\mathrm{N}_{\text {out }}-\mathrm{C}_{\text {out }}$ topology (refer to Additional files $2 \mathrm{~A}$ and 2B for high-magnification CLSM and differential permabilization assays with p36 90-190-CAT).
Characterization of the mitochondrial targeting information in p36 was also carried out using domain-swapping assays with TBSV p33, an ortholog of CymRSV that has been recently well characterized in terms of its peroxisomal membrane targeting signal [25]. Alignment of the deduced amino acid sequences for p 36 and p33 revealed that while these proteins are nearly identical in their C-terminal halves, they are significantly divergent with respect to their $\mathrm{N}$ termini (Figure 4A). For instance, although both proteins are predicted to contain two TMDs located at relatively similar positions within their $\mathrm{N}$-terminal halves (underlined, Figure 4A), p36 also possesses a number of amino acid residues in this region of the protein that are not found in $\mathrm{p} 33$. The most conspicuous of these being stretches of unique residues located near the extreme $\mathrm{N}$ terminus and within the intervening loop sequence of p36 (Figure 4A). Alignment of the p36 and p33 sequences revealed also that the multiple targeting signal motifs responsible for sorting nascent p33 initially to peroxisomes (i.e., $-\mathrm{K}_{11} \mathrm{~K}_{12^{-}}, \mathrm{K}_{76} \mathrm{RRQR}_{80^{-}}$and $\mathrm{R}_{124}$ PSVPKK $_{130^{-}}$) (shaded in grey in Figure $4 \mathrm{~A}$ ) and then from peroxisomes to a subdomain of the endoplasmic 
A

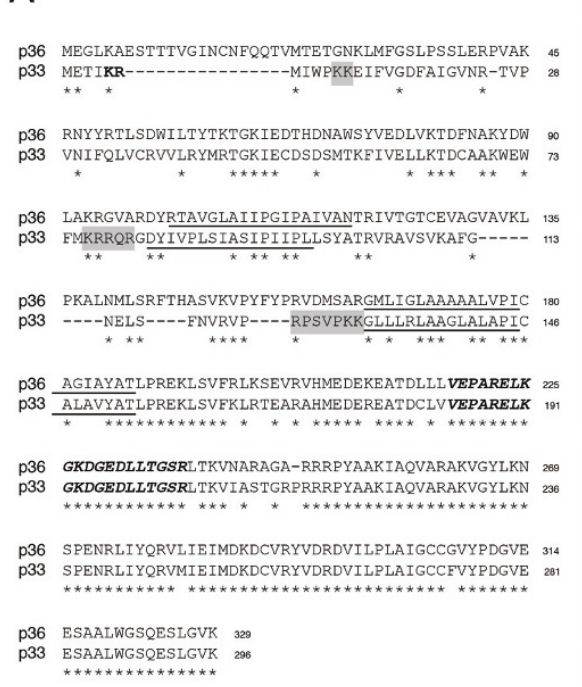

B

Construct

p36-myc

p33-myc

p36 1-190 p33-myc

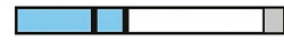

p33 1-156 p36-myc

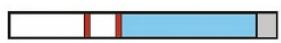

p36 1-120 p33-myc

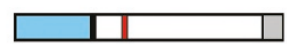

p33 103-131 p36-myc

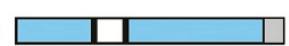

p36 120-190 p33-myc

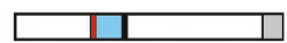

p33 103-156 p36-myc

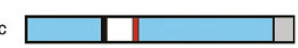

Localization

Mito

Perox

Mito

Perox

Cyt

Cyt

Perox \& Mito

Perox \& Cyt

C
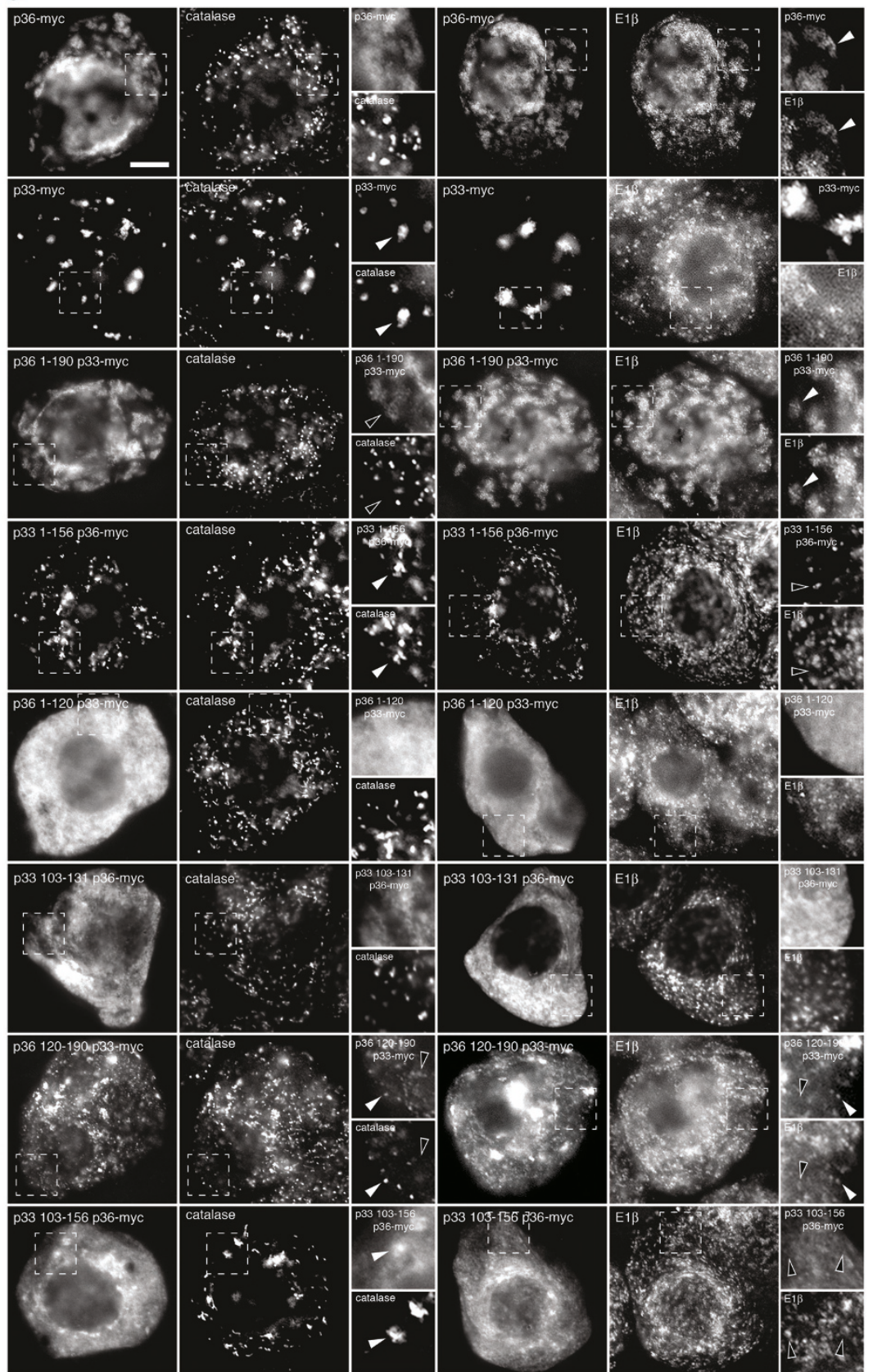

\section{Figure 4}

Localization of p36-p33 hybrid proteins in BY-2 cells. (A) Alignment of the deduced amino acid sequences of CIRV p36 and TBSV p33. Sequences were obtained from GenBank and aligned using the ClustalW http://npsa-pbil.ibcp.fr/cgi-bin/npsa automat.pl?page=npsa clustalw.html. Identical amino acids in each protein are indicated with asterisks and putative TMDs (underlined) were determined using TMHMM (version 2.0) and visual inspection.

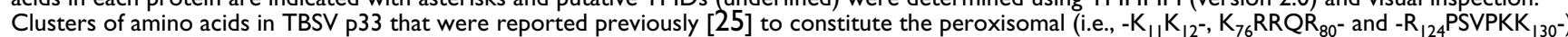
or $p E R$ (i.e., $-K_{5} R_{6}-$ ) targeting signals are shaded grey or bolded, respectively. Conserved residues in p33 (residues 184-203) and p36 (residues 218-237) that are immunorecognized by a polyclonal antibody raised against this (synthetic) peptide sequence [25] are italized and bolded. (B) Schematic illustrations of C-terminal myc-tagged p36 (p36-myc), p33 (p33-myc) and various p36-p33 hybrid proteins and their corresponding subcellular localizations in transformed (via biolistic bombardment) tobacco BY-2 cells. The numbers in the name of each hybrid construct denote the specific amino acid residues from p36 or p33 that were fused to (trunctated) p33-myc or p36-myc, respectively. Portions of the p36 ORF are colored blue or black, the latter denoting the two putative TMDs in $\mathrm{p} 36$ and the numbers shown above p36-myc indicating their relative amino acid positions. Similarly, portions of the p33 ORF are colored white and red, the latter denoting the two putative TMDs in p33 and the numbers shown above p33-myc indicating their relative amino acid positions. The grey colored box for each construct denotes the C-terminal appended myc epitope. Cyt, cytosol; Mito, mitochondria; Perox, peroxisome. (C) Representative (immuno)epifluorescence micrographs illustrating the localizations of the various constructs shown in (B). Each micrograph is labelled at the top left with the name of either the transiently-expressed protein, the endogenous mitochondrial matrix marker protein EI $\beta$, or the endogenous peroxisomal matrix marker protein catalase. Hatched boxes represent the portion of the cells shown at higher magnification in the panels to the right. Solid arrowheads indicate obvious colocalizations; open arrowheads indicate obvious non-colocalizations. Bar $=10 \mu \mathrm{m}$. 
reticulum (ER) referred to as peroxisomal ER (pER) (i.e., $\mathrm{K}_{5} \mathrm{R}_{6^{-}}$) (bolded in Figure 4A) [25] are not conserved in p36, consistent with the apparently distinct intracellular sorting pathways employed by these two proteins.

As shown in Figures 4B and 4C, p36-myc and p33-myc (TBSV p33 appended to a C-terminal myc-epitope tag) sorted exclusively to aggregated mitochondria and peroxisomes, respectively, in transiently-transformed BY-2 cells. The aggregation of peroxisomes in p33-myc-transformed cells is apparent by comparing the immunostaining pattern attributable to the endogenous peroxisomal matrix enzyme catalase in these cells with that of p36-myc-transformed cells, wherein catalase-containing peroxisomes display a normal (punctate) morphology and distribution (Figure 4C). These data for the localization of p33-myc to altered peroxisomes was expected, since previously published results with wild-type (non-tagged) p33 expressed for the same length of time (i.e., $4 \mathrm{~h}$ following biolistic bombardment) revealed that it was localized exclusively to peroxisomes and caused the organelles to coalesce [25]. Also similar to wild-type p33 [25], p33-myc sorted from peroxisomes to pER at later time points following bombardment (i.e., $24 \mathrm{~h}$ ) (data not shown), indicating that the myc epitope also did not disrupt the normal peroxisome-to-pER sorting of the protein. Nevertheless, in order to minimize any potential sorting complexities associated with the targeting of $\mathrm{p} 33$ from peroxisome to $\mathrm{pER}$ at later time points, all of p33/p36-myc hybrids employed in domain-swapping assays were assessed only at $4 \mathrm{~h}$ postbombardment for peroxisomal versus mitochondrial targeting.

Replacement of the N-terminal half of p33 (residues 1156) with the corresponding sequences from p36 (residues 1-190), including the N-terminal hydrophilic domain and both TMDs plus the intervening loop sequence, resulted in the hybrid protein (p36 1-190 p33myc) being sorted to aggregated mitochondria, but not to peroxisomes (Figure 4C). Conversely, p33 1-156 p36myc, consisting of the N-terminal half of p33, including all three of the protein's peroxisomal targeting signals (i.e., $-\mathrm{K}_{11} \mathrm{~K}_{12^{-}}, \mathrm{K}_{76} \mathrm{RRQR}_{80^{-}}$and $-\mathrm{R}_{124} \mathrm{PSVPKK}_{130^{-}}$; refer to Figure 4A) [25], fused to the C-terminal half of p36, sorted exclusively to peroxisomes in a manner similar to fulllength p33-myc (Figure 4C).

Figures $4 \mathrm{~B}$ and $4 \mathrm{C}$ show also that fusion of the N-terminal 120 amino acids of p36 (including the protein's N-terminal hydrophilic domain and first TMD) to the remaining C-terminal portion of p33-myc resulted in the hybrid protein (p36 1-120 p33-myc) being localized to the cytosol, a result similar to when this $\mathrm{N}$-terminal region of $\mathrm{p} 36$ was fused to CAT (p36 1-120-CAT) (Figure 3). Localization to the cytosol was observed also when the intervening loop sequence from p36 was replaced with the loop sequence from p33 (p33 103-131 p36-myc), indicating that this region of p36 contains essential mitochondrial targeting information. In accordance with this premise, the p36 intervening loop sequence together with its second TMD was capable of redirecting, albeit inefficiently, p33-myc to mitochondria, i.e., p36 120-190 p33-myc was sorted to both mitochondria and peroxisomes (Figure 4C), and further showing that this hybrid protein contains targeting information for both organelles. By contrast, mitochondrial targeting of p36 was completely abolished when its intervening loop sequence and TMD2 was replaced with the corresponding sequences from p33 (residues 103$156)$, i.e., p33 103-156 p36-myc was not localized to mitochondria, but instead localized to both peroxisomes and the cytosol (Figure 4C). The apparent inefficient sorting of this hybrid protein to peroxisomes is likely due to the fact that it possessed only one of the three peroxisomal targeting signals within $\mathrm{p} 33$, i.e., $-\mathrm{R}_{124} \mathrm{PSVPKK}_{130^{-}}$(refer to p33 sequence shown in Figure 4A).

Overall, the data presented in Figures 3 and 4 confirm and extend the observations of Weber-Lotfi et al. [18] that the minimally sufficient mitochondrial targeting information in p36 is located within protein's N-terminal half, including both TMDs and the intervening loop sequence. Additional flanking sequences immediately upstream and downstream of TMD1 and TMD2, respectively, are not essential, however, for targeting p36 to mitochondria. For instance, the N-terminal hydrophilic portion of p36 was insufficient in sorting CAT (Figure 3) or a p36/p33 hybrid protein containing the remaining $\mathrm{C}$ terminal portion of p33 (Figure 4) to mitochondria. Thus, our data contradict the previously proposed notion that the N-terminal hydrophilic domain of $\mathrm{p} 36$, specifically, the residues immediately upstream of TMD1, contain a distinct mitochondrial targeting determinant [18]. It appears instead that p36 contains only one mitochondrial targeting signal: a signal that consists of a relatively large portion of the protein (residues 90-190) and includes several different structural elements, i.e., two TMDs and an intervening soluble loop sequence. The relative contribution of these elements likely mediates the various aspects of p36 biogenesis including maintaining solubility before membrane insertion, targeting to mitochondria, and/or ensuring proper assembly in the mitochondrial outer membrane.

\section{The moderate hydrophobicity of TMDI and TMD2 is essential for targeting $p 36$ to mitochondria}

The results presented above indicate that the sorting of p36 to mitochondria is, at least in part, dependent upon its TMDs. Thus, to test whether specific amino acid sequences or more global properties, e.g., overall hydrophobicity and/or length, within one or both of the TMDs 
contribute important mitochondrial targeting information, we generated several different mutant versions of p36-myc containing altered TMD sequences (Figure 5A). Included among these p36 TMD mutants were those that contained sequences derived from either TBSV p33 or the mitochondrial outer membrane-localized isoform of cytochrome $b_{5}$ (Cb5), a tail-anchored protein whose mitochondrial targeting signal consists of several unique physicochemical and sequence-specific characteristics within its single C-terminal TMD and hydrophilic tail domain [27]. By replacing TMD1 or TMD2 in p36 with either the corresponding TMDs from p33 or the TMD from Cb5 (and vice versa, i.e., Cb5 with its TMD exchanged for
TMD1 or TMD2 from p36), we sought to determine what role the p36 and p33 TMDs play in mitochondrial versus peroxisomal targeting and, in the case of p36 and Cb5, whether these two proteins possess functionally equivalent mitochondrial targeting information within their TMDs.

As shown in Figure 5B, when the sequences for TMD1 and TMD2 in p36 were exchanged the resulting mutant protein (p36-myc TMD1 $\Leftrightarrow$ TMD2) localized exclusively to mitochondria. Interestingly, the morphology and distribution of the mitochondria in these cells, unlike in wildtype p36-myc-transformed cells (refer to Figure 1), did not
A

Construct

p36-myc TMD2 $\Leftrightarrow$ TMD1

p36-myc TMD1 $\triangle$ synTMD

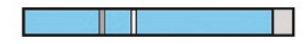

p36-myc TMD2 synTMD

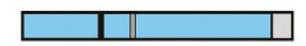

p36-myc TMD1/TMD2 $\Delta$ synTMD

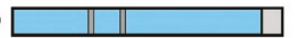

p36-myc TMD1 $\triangle$ Cb5TMD

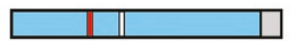

p36-myc TMD2 $\triangle$ Cb5TMD

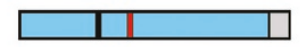

p36-myc TMD1 $\triangle$ p33TMD1

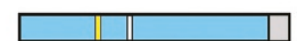

p36-myc TMD2 $\triangle$ p33TMD2

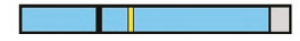

myc-Cb5

myc-Cb5 TMD $\triangle$ p36TMD1

myc-Cb5 TMD $\Delta$ p36TMD2

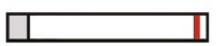

\section{B}

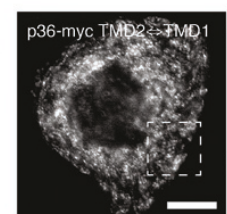

Cyt \& ?

Cyt \& ?

Cyt \& ?

Cyt

Cyt

Mito

Mito

Mito

Cyt

ER / Mito
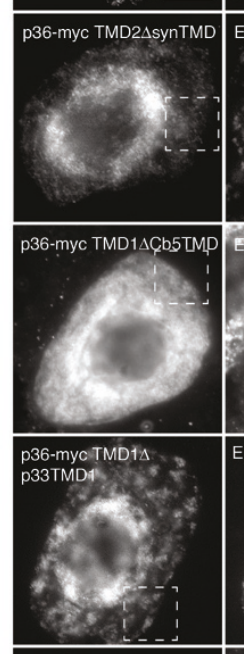
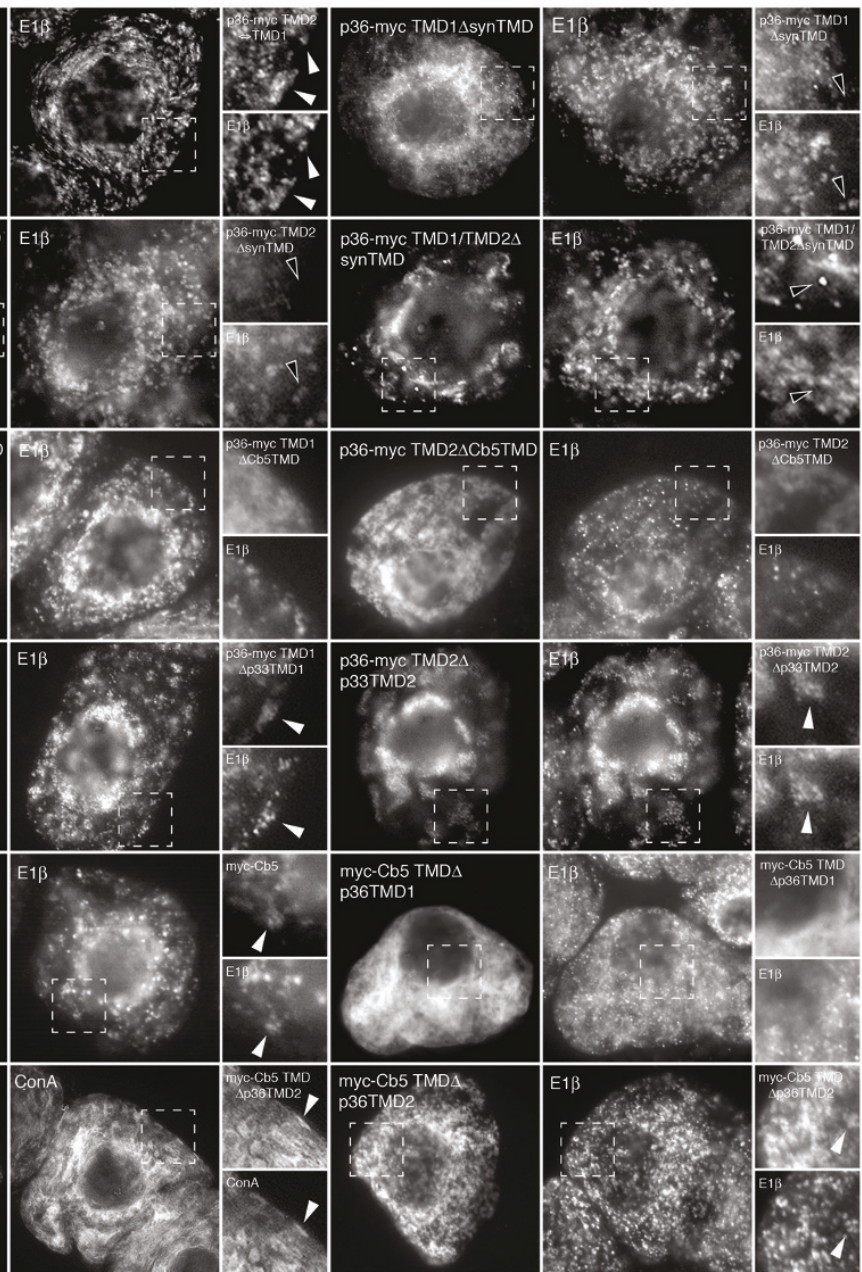

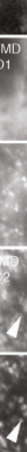

\section{Figure 5}

Localization of p36 and Cb5 proteins with modified TMDs in BY-2 cells. (A) Schematic illustrations of various p36-myc and myc-Cb5 proteins with modified TMDs and their corresponding subcellular localizations in transformed (via biolistic bombardment) BY-2 cells. The name of each mutant construct denotes p36-myc or myc-Cb5 and the specific alterations to its TMD(s). Hydrophilic portions of the p36 ORF are colorized blue, with TMDI and TMD2 in p36 colored black and white, respectively. The single TMD in Cb5 is colorized red. Grey boxes denote the position of the myc epitope. Cyt, cytosol; ER, endoplasmic reticulum; Mito, mitochondria; ?, unknown subcellular compartment(s). (B) Representative (immuno)epifluorescence micrographs illustrating the localizations of the various constructs shown in (A). Each micrograph is labelled at the top left with the name of either the transiently-expressed protein, the endogenous mitochondrial marker protein, EI $\beta$, the endogenous peroxisomal marker protein, catalase, or ConA (fluorconjugated Concanavalin A) serving as stain for the ER [89,98]. Hatched boxes represent the portion of the cells shown at higher magnification in the panels to the right. Solid arrowheads indicate obvious colocalizations; open arrowheads indicate obvious non-colocalizations. Bar $=10 \mu \mathrm{m}$. 
appear to be altered (e.g., aggregated). These data suggest that the relative positions of the two TMDs within p36 influence the effects that this protein has on mitochondria morphology/distribution, but not its intracellular sorting.

An examination of the TMD amino acid sequences within p36 (underlined, Figure 4A) did not reveal any noticeable conserved features. For instance, with the exception that both TMDs possess similar (moderate) average hydrophobicity indexes (according to the Kyte-Doolittle algorithm [28]) of 1.58 (TMD1) and 2.05 (TMD2), they vary in their overall length (i.e., TMD1 is predicted to be 18 amino acid residues long, whereas TMD2 is 23 residues long). Moreover, they contain no obvious conserved amino acid sequence-specific motifs or an enrichment of particular amino acid residues. Therefore, the possibility was tested that the overall hydrophobic nature of the TMDs was the functional determinant in sorting p36 to mitochondria. Toward this end, either TMD1 or TMD2, or both TMDs together, in p36 were replaced with artificial (idealized) amino sequences composed of multiple -LALV-repeats [29] while still maintaining the length of the TMDs in p36, i.e., 18- and 23-long repeats of -LALV-corresponding to the length of TMD1 and TMD2 in p36, respectively. As shown in Figure 5B, all three of the resulting mutant versions of p36-myc (i.e., p36-myc TMD1 2 synTMD, p36myc TMD2 $\Delta$ synTMD and p36-myc TMD1/ TMD2 $\Delta$ synTMD) mislocalized to cytosol and to some unknown punctate compartment(s) that did not colocalize with endogenous mitochondrial E1 $\beta$ (refer to open arrowheads in high magnified views shown in Figure 5B), nor peroxisomal catalase (data not shown). Similarly, replacement of TMD1 or TMD2 in p36 with the 18 aminoacid long single TMD from the mitochondrial isoform of Cb5 [27] resulted in both mutant proteins (p36-myc TMD1 $\Delta$ Cb5TMD and p36-myc TMD2 $\Delta$ Cb5TMD) being mislocalized to the cytosol. By contrast, both p36-myc TMD1 $\Delta$ p33TMD1 and p36-myc TMD2 2 p33TMD2 in which TMD1 or TMD2 of p36 were replaced with TMD1 or TMD2 from p33, respectively, sorted to (aggregated) mitochondria in a manner similar to wild-type p36-myc (Figure 5B).

As shown also in Figure 5B, N-terminal myc-tagged Cb5 (myc-Cb5) localized exclusively to mitochondria, as previously published [27]. Replacement of the single TMD in myc-Cb5 with TMD1 or TMD2 from p36, however, resulted in the corresponding mutant proteins being mislocalized either to the cytosol (myc-Cb5 $\Delta$ p36TMD1) or to the ER (myc-Cb5 $\Delta$ p36TMD2) (Figure 5B); although in a small proportion ( $15 \%)$ of the cells transformed with myc-Cb5 $\Delta$ p36TMD2 the mutant protein targeted to mitochondria in a manner similar to that of wild-type mycCb5 (Figure 5B).
Together, the data presented in Figure 5 imply that not all hydrophobic sequences are sufficient to replace TMD1 or TMD2 in p36 in terms of mediating its proper targeting to mitochondria. However, a pertinent question based on these data is why the TMDs from p33, a peroxisomal membrane-localized protein $[15,25,30,31]$, but not an idealized hydrophobic TMD, nor the TMD from an authentic mitochondrial outer membrane protein Cb5 [27], are capable of preserving the targeting of p36 to mitochondria? One possibility is that the relatively moderate overall hydrophobicity of the TMDs in p36 is an essential feature of the protein's mitochondrial targeting signal. Based on this premise, the mislocalization of p36 when one (or both) of its TMDs was replaced with either an artificial TMD(s) or the Cb5 TMD was due to the relatively high hydrophobic indexes of these introduced sequences, i.e., 3.33 and 3.36 for the 18 and 23 amino acid-long synthetic TMDs and 2.42 for the 18 amino acidlong Cb5 TMD, compared to those for p36 TMD1 (1.58) and TMD2 (2.05). By contrast, the mitochondrial targeting of p36 was not disrupted when its TMDs were replaced individually with the relatively moderate hydrophobic TMDs from p33, i.e., 2.01 and 1.98 for TMD1 and TMD2, respectively.

This scenario that the mitochondrial sorting of p36 is mediated, at least in part, by the moderate hydrophobic nature of its TMDs is in agreement with results from several other studies on the sorting of authentic mitochondrial outer membrane proteins. That is, depending on the protein, a moderate hydrophobic $\operatorname{TMD}(\mathrm{s})$, combined with positive charges at its flanking soluble regions, is essential for mitochondrial outer membrane targeting [reviewed in [32,33]]. For example, the $20-\mathrm{kD}$ and $70-\mathrm{kD}$ subunits of the TOM complex (TOM20 and TOM70) and TOM45 (a mitochondrial outer membrane protein of 45 $\mathrm{kD})$ from yeast all contain moderately hydrophobic TMDs that are functionally interchangeable in terms of their targeting behaviour [34]. The mammalian (human) TOM20 and yeast mitochondrial outer membrane protein fission 1 (FIS1) also appear to rely on the moderate hydrophobicity of their TMDs, since increasing their overall hydrophobic score via mutagenesis resulted in both modified proteins being mislocalized [35,36]. Conversely, reducing the overall hydrophobicity of an artificial TMD within a yeast ER-localized reporter membrane protein by introducing one or more hydrophilic residues caused it to relocalize from the ER to mitochondria [37].

A notable extension of this model is that, for at least some mitochondrial outer membrane proteins, they appear to rely also on subtle sequence-specific features within their TMDs. For instance, both the yeast $5-\mathrm{kD}$ and $7-\mathrm{kD}$ TOM subunits (TOM5 and TOM7) possess a conserved proline residue near the center of their TMDs that is required for 
their efficient targeting to mitochondria [38,39]. While the precise role of this proline in the mitochondrial targeting of these proteins has not been determined, it may be due to the residue's ability to destabilize the TMD's $\alpha$-helical structure and, thus, dictate its overall configuration and subsequent interaction with the proper cognate receptor and/or integration/assembly factor(s) [32]. Interestingly, targeting of mitochondrial plant Cb5 also appears to rely on a conserved proline residue that forms part of a short hydrophilic surface situated within the protein's TMD [27]. Based on this, it is perhaps not surprising that replacement of the Cb5 TMD with either TMD1 or TMD2 from p36 resulted in both of the modified Cb5 proteins being either completely (myc-Cb5 $\Delta$ p36TMD1) or partially (myc-Cb5 $\Delta$ p36TMD2) mislocalized within cells (Figure $5 \mathrm{~B}$ ). That is, the nature of the targeting information within the TMDs of p36 and Cb5 appear to be sufficiently distinct in terms of their relative overall hydrophobicity and the presence (or the lack) of sequence-specific motifs, such that they are not functionally interchangeable. As discussed below, these apparent differences in the targeting elements within the TMDs of p36 and Cb5 also appear to reflect the relative contribution of unique positively-charged targeting elements at their flanking regions.

\section{The intervening loop sequence of p36 contains an amphipathic helix with a positively-charged face that is essential for mitochondrial targeting}

Since the intervening loop sequence in p36 (residues 120-165 between TMD1 and TMD2) is significantly divergent from the corresponding loop sequence in peroxisomal-targeted p33 (Figure 4A) and since replacement of this region in p36 with that from p33 resulted in the hybrid protein (p33 103-131 p36-myc) being mislocalized to the cytosol (Figure 4B), we analyzed this region in p36 to determine if it contained any distinctive features involved in mitochondrial targeting. Figure 6A shows that

A

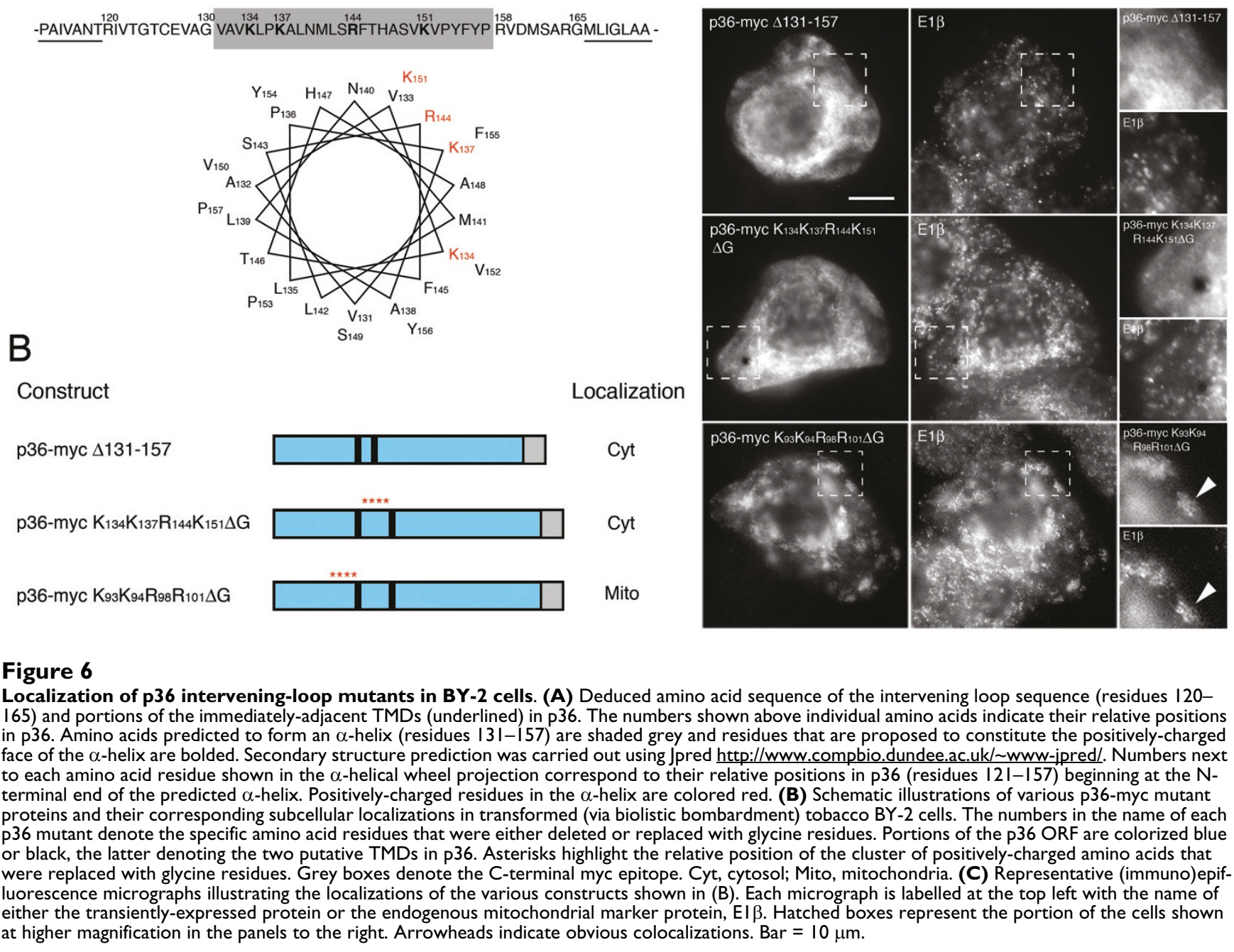


the deduced amino acid sequence of the p36 intervening loop, specifically the central portion of this sequence that is devoid in p33 (residues 131-157, shaded in Figure 6A; refer also to Figure 4A), is enriched in both positivelycharged (bolded) and hydroxylated (i.e., Ser, Thr and Pro) amino acid residues. This central region of the p36 intervening loop also has the propensity (based on secondary structure prediction programs) to form an $\alpha$-helix, one with amphipathic characteristics conveyed by a positivelycharged face (refer to amino acid residues in red; Figure $6 \mathrm{~A})$.

Based on these observations and previous reports that the targeting of several other authentic mitochondrial outer membrane-destined proteins rely on positively-charged residues together with a flanking $\operatorname{TMD}(\mathrm{s})[32,33]$, we examined further the positively-charged face of the amphipathic helix in p36 by mutational analyses. As shown in Figures $6 \mathrm{~B}$ and $6 \mathrm{C}$, deletion of amino acid residues 131-157 in p36-myc resulted in the mutant (i.e., p36-myc $\Delta 131-157)$ being mislocalized to the cytosol. These data are consistent with the mislocalization of $\mathrm{p} 36$ myc when its intervening loop sequence was replaced with that of p33 (i.e., p33 103-131 p36-myc; Figure 4B).

Mitochondrial targeting of p36-myc was also abolished when glycine residues were exchanged for each of the four positively-charged residues predicted to be situated along the same face of the amphipathic $\alpha$-helix within the protein's intervening loop sequence, i.e., p36-myc $\mathrm{K}_{134} \mathrm{~K}_{137} \mathrm{R}_{144} \mathrm{~K}_{151} \Delta \mathrm{G}$ mislocalized to the cytosol (Figure 6C). By contrast, glycine substitutions of another cluster of positively-charged residues (i.e., $\mathrm{K}_{93} \mathrm{~K}_{94} \mathrm{R}_{98} \mathrm{R}_{101}$ ) located immediately upstream of TMD1 did not disrupt the sorting of p36-myc to mitochondria (p36-myc $\mathrm{K}_{93} \mathrm{~K}_{94} \mathrm{R}_{98} \mathrm{R}_{101} \Delta \mathrm{G}$; Figure $6 \mathrm{C}$ ). These latter results, as well as those presented earlier for the mislocalization of p36 1120-CAT (Figure 3) and p36 1-120 p33-myc (Figure 4) reinforce our conclusion that, in contrast to the findings reported by Weber-Lotfi et al. [18], the N-terminal hydrophilic region located upstream of TMD1 in p36 does not contain mitochondrial targeting information.

The results for p36-myc $K_{93} K_{94} R_{98} R_{101} \Delta G$ also indicate that not all mutations to the protein affected its mitochondrial targeting fidelity. An observation that underscores a substantive caveat of this study (and any analysis of membrane protein targeting) whereby mutations of p36 that resulted in the protein's mislocalization could have been due to aberrant protein folding, rather than a disruption of a specific targeting determinant(s). Although this possibility cannot be excluded, our combined use of loss-of-function and gain-of-function targeting assays strongly supports our definition of the bona fide mitochondrial targeting information within p36.
Collectively, our findings on the combined importance of positively-charged residues (Figure 6) and moderate hydrophobic TMDs (Figure 5) in the mitochondrial targeting of p36, as well as the $\mathrm{N}_{\text {out }}{ }^{-} \mathrm{C}_{\text {out }}$ topological orientation of the protein in the mitochondrial outer membrane (Figure 2), suggests that the insertion and assembly of p36 involves a signal loop-anchor mechanism [40]. That is, interaction of the positively-charged residues in the intervening loop sequence of nascent $\mathrm{p} 36$ with the mitochondrial outer surface might promote a conformational change that drives insertion of its moderate hydrophobic TMDs into the bilayer, and results in the proper $\mathrm{N}_{\text {out }}-\mathrm{C}_{\text {out }}$ topology. This proposed signal loop-anchor mechanism is consistent, as mentioned above, with results from previous in vitro insertion experiments with $\mathrm{p} 36$ and isolated mitochondria [18]. Moreover, since the topological orientation of p36 is identical to the topology of the authentic outer mitochondrial membrane proteins yeast fuzzy onion 1 (Fzo1) and its mammalian homologs, mitofusin (Mfn) 1 and 2, i.e., anchored in an $\mathrm{N}_{\text {out }} \mathrm{C}_{\text {out }}$ manner by two $\alpha$-helical TMDs connected via a short loop sequence located in the intermembrane space [41,42], it is possible that the signal loop-anchor insertion of p36 is mediated by the same mitochondrial machinery that is utilized by Fzo1 and Mfn1/2. Results of experiments aimed at addressing this possibility are described next.

\section{p36 interacts with certain components of the mitochondrial TOM complex, but not with the mitochondrial SAM complex}

Almost all mitochondrial proteins are encoded by nuclear genes, synthesized on free polyribosomes in the cytosol, and targeted post-translationally to the organelle. Thereafter, the recognition, translocation, and sorting of these proteins is usually mediated by the TOM complex and, depending on the protein's submitochondrial destination, one of several other translocase complexes located in the outer and inner mitochondrial membranes [reviewed in [43-45]]. For instance, based on studies carried out primarily with yeast and mammalian model systems, it is well established that nascent proteins destined for the mitochondrial matrix or inner membrane are recognized by the import receptors TOM 20 and TOM70 and then delivered to one of two discrete translocase of the inner mitochondrial membrane (TIM) complexes. The majority of proteins destined for the outer mitochondrial membrane in yeast and mammals also rely on the TOM complex, but appear to do so in a number of different ways depending on their topology [reviewed in [33]]. For example, mitochondrial outer membrane proteins with multiple $\alpha$-helical TMDs, including Mfn1/2, utilize the receptor TOM70, but not other components of the TOM complex [46]. $\beta$-barrel outer mitochondrial membrane proteins, such as porin and the channel forming subunit of the TOM complex, TOM40, as well as C-terminal tail- 
anchored subunits of the TOM complex (i.e., TOM22, TOM5, TOM6 and TOM7), are recognized mainly by TOM 20 and then subsequently transferred to the SAM complex [47], a hetero-oligomeric complex located in the mitochondrial outer membrane where it functions in $\beta$ barrel protein insertion and assembly $[33,48]$. Interestingly, another subset of C-terminal, tail-anchored outer membrane proteins, including BAX and FIS1, do not require any known import (TOM) components, but instead appear to rely on the unique lipid composition of the mitochondrial outer membrane for their proper targeting and insertion $[49,50]$.

While it is generally accepted that the various mitochondrial import pathways and associated machinery are conserved among evolutionarily diverse organisms including yeast, animals and plants, considerable differences exist among some of their core protein subunit compositions and functional specificities, particularly in plants [51,52]. Thus, p36 may or may not use the same mitochondrial insertion machinery in plants as that employed by multispanning mitochondrial outer membrane proteins in yeasts and mammals, such as the TOM70-dependent targeting of Mfn $1 / 2$ [46]. The targeting and insertion of $\mathrm{p} 36$ may be also more similar to that of yeast FIS1, which is mediated primarily by the distinct lipid composition of the mitochondrial outer membrane [50], a possibility that appears to be consistent with previous data indicating that p36 does not to rely on any mitochondrial-surface proteinaceous receptors [18]. This latter conclusion, however, was based solely on the observation that pre-treatment of isolated mitochondria with trypsin to remove any exposed parts of surface receptors did not prevent membrane insertion of $\mathrm{p} 36$. Indeed, this apparent lack of sensitivity to trypsin is not evidence $a$ priori that p36 import does not utilize a proteinaceous receptor(s), since mitochondrial surface receptors can display differences in terms of their sensitivity/resistance to an applied protease $[53,54]$ and can even be bypassed in vitro such that a chloroplast protein can be imported into protease-pretreated mitochondria with the same efficiency as a mitochondrial protein that normally relies on a surface receptor [55].

To determine the insertion pathway of p36 into the outer mitochondrial membrane we tested whether it could interact directly with a variety of protein components of the plant TOM and/or SAM complexes. Specifically, we employed bimolecular fluorescence complementation (BiFC) assays to determine whether in vivo physiological interactions occur between p 36 and four Arabidopsis TOM protein subunits including: i) the TOM20 import receptor [56-58]; ii) TOM22, which may function in a manner similar to yeast and mammalian TOM 22 by providing some receptor function, but mostly as a link between the primary receptors TOM20 and TOM70 [59]; iii) TOM40, the central pore-forming subunit of the TOM complex [56]; and iv) mtOM64 (outer mitochondrial membrane protein of $64-\mathrm{kD}$ ), which functions as an import receptor and, based on structural similarities, may be a paralog of yeast and mammalian TOM70 [52,60]. We also tested whether p36 physically interacts with Arabidopsis METAXIN, a diverged form of the SAM component SAM 37 and METAXIN1 in yeasts and mammals, respectively $[52,61]$.

BY-2 cells were transiently transformed with pairs of plasmids encoding $\mathrm{p} 36$ fused at its $\mathrm{C}$ terminus to the $\mathrm{C}$-terminal half of the modified yellow fluorescent protein Venus [62] (cVenus) and one of the TOM or SAM proteins fused at either their $\mathrm{N}$ or $\mathrm{C}$ termini to the $\mathrm{N}$-terminal half of Venus (nVenus) (e.g., nVenus-TOM20); refer to illustrations of various proteins in Figure 7B showing their predicted topological orientations in the mitochondrial outer membrane and the relative location of their appended Venus fragment. Because each half of Venus is not intrinsically fluorescent, Venus fluorescence is observed only when intermolecular interactions occur between nVenusand cVenus-tagged proteins [63-65], highlighting an advantage of BiFC over other protein-protein interaction assays (e.g., yeast two-hybrid and immunoprecipitations) in that the subcellular localization of the interacting proteins can directly be observed in living cells via microscopy. All cells were also co-bombarded with a third plasmid encoding the red fluorescent protein (RFP), which served as an internal standard for transformation efficiency and aided in identifying transformed cells.

Alternatively, BY-2 cells were co-bombarded with a plasmid coding for an individual nVenus- or cVenus-tagged protein along with a plasmid encoding $\beta$ ATPase-GFP (consisting of the $\mathrm{N}$-terminal mitochondrial matrix targeting presequence of $\beta$ ATPase [residues 1-60] fused to the $\mathrm{N}$ terminus of GFP), which served to identify transformed cells and, acting as a well-characterized mitochondrial marker protein [66,67]. As presented in Additional file $3 \mathrm{~A}$, results from these latter experiments provided confirmation of the expression of each of the individual Venus half fusion proteins (via immunomicroscopy of an appended myc or hemaglutinin (HA)-epitope tag; see Methods and Materials for details on the construction of BiFC plasmids), as well as their mitochondrial localization. Additional results confirming the topological orientation of several of these Venus half fusion proteins in BY2 cells using the differential detergent permeabilization assay are presented in Additional file 3B.

The results presented in Figure 7A show that p36 (i.e., p36-cVenus) interacted in vivo with all three of the nVenus-tagged versions of the putative import receptors, TOM20, TOM22 and mtOM64. Notably, the interaction 
A

\begin{tabular}{lccccc}
\hline & p36 & BATPase & porin & p33 & Cb5 \\
\hline TOM20 & + & + & + & - & ND \\
TOM20mut & + & - & + & ND & ND \\
TOM22 & + & + & + & - & ND \\
TOM40 & - & - & - & - & ND \\
miOM64 & + & + & + & - & ND \\
METAXIN & - & - & + & ND & ND \\
p36 & - & ND & - & - & - \\
& & & & & \\
\hline
\end{tabular}

B

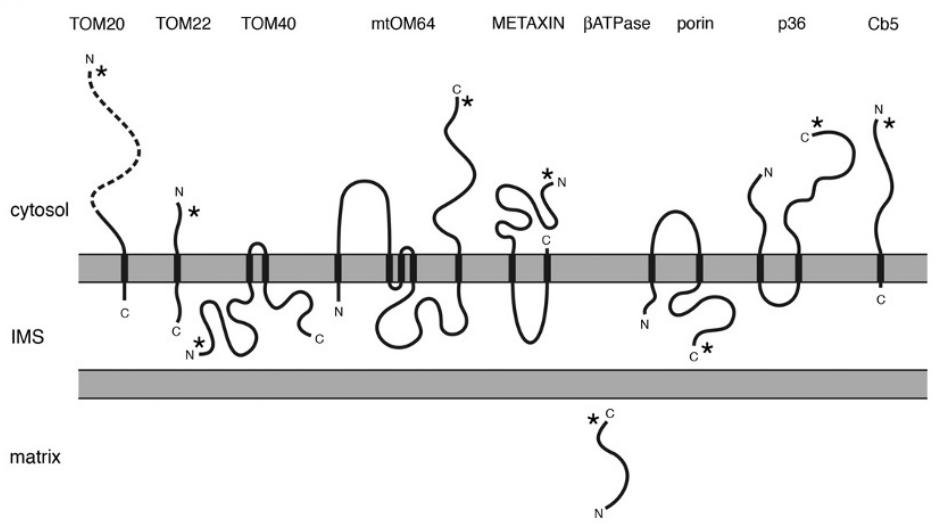

\section{Figure 7}

BiFC analysis of interactions among p36 and components of the TOM and SAM complexes. (A) BY-2 cells were co-transformed (via biolistic bombardment) with either $\mathrm{p} 36$, the $\mathrm{N}$-terminal mitochondrial matrix targeting presequence of the $\beta$ subunit of the $\mathrm{F}_{1}-\mathrm{ATPase}$ ( $\beta$ ATPase), porin, $\mathrm{p} 33$, or $\mathrm{Cb} 5$ fused at either their $\mathrm{N}$ or $\mathrm{C}$ termini to cVenus (columns) and various constituents of the TOM complex (or an $\mathrm{N}$-terminal mutant version of TOM20; TOM20mut), METAXIN, or p36 fused at either their $\mathrm{N}$ or $\mathrm{C}$ termini to nVenus (rows). In addition, all cells were co-transformed with either RFP, which served as a convenient means of identifying transformed cells. At $\sim 16 \mathrm{~h}$ post-bombardment, cells were formaldehyde fixed and viewed by epifluorescence microscopy. Interactions were scored based on either the presence (+) or absence $(-)$ of a BiFC (Venus) signal relative to reconstitution controls in which individual Venus half fusion proteins were co-expressed with the corresponding "empty" vector containing nVenus or cVenus fragments alone. All BiFC signals observed co-localized with (co)expressed mitochondrial $\beta$ ATPase-GFP. For each pair of plasmids tested, $>25$ transformed cells were scored from at least two independent transformation (biolistic bombardment) experiments. ND, not determined. (B) Predicted topologies of mitochondrial outer membrane proteins used in BiFC experiments, the results of which are presented in (A). Also shown is the localization of the soluble $\beta$ ATPase N-terminal mitochondrial targeting presequence in the matrix following import. The topological orientations of mitochondrial outer membrane proteins shown are based on differential permeablization results presented either in Figure 2 (for $\mathrm{p} 36$ ), in Additional file 3A (for TOM proteins, METAXIN, and porin) or published previously in Hwang et al. [27] (for $\mathrm{Cb} 5$ ). Regions of proteins proposed to be hydrophobic membrane-spanning domains or hydrophilic domains facing the cytosol, intermembrane space or matrix were identified using the TMpred program http://www.ch.embnet.org/software/TMPRED form.html. The dashed line in the $\mathrm{N}$-terminal portion of TOM20 represents the region of the receptor that was deleted in the corresponding mutant (TOM20 $\left.{ }_{m y}\right)$; specifically, protein's $\mathrm{N}$-terminal I-I42 residues including the tetratricopeptide motif-based receptor domain for mitochondrial precursor proteins [58]. Asterisks indicate the relative position of nVenus or cVenus and the immediately adjacent myc- or HA-epitope tag appended to each protein. IMS, intermembrane space.

of p36 with TOM20 was unaffected when the receptor protein's N-terminal tetratricopeptide motif-based domain responsible for the recognition and interaction with mitochondrial precursor proteins (residues 1-142; [58]) was deleted (TOM20mut), suggesting that the interaction of p36 with the TOM20 is not mediated by this substrate-receptor-binding motif. p36 did not interact, however, with either TOM40, the SAM component METAXIN, or itself (i.e., p36-nVenus) (Figure 7A). While these latter data appear to contradict those published elsewhere for the homo-oligmerization of the p36-related protein, TBSV p33 [[68] and references therein] and, p36p36 and other p36-protein interactions likely occur within the context of the functional CIRV replication complex and, thus, mediated by the allied replication protein, p95, as well viral RNA template [69].

In a series of control experiments we also evaluated whether or not the $\beta$ ATPase matrix targeting presequence and/or the full-length outer mitochondrial $\beta$-barrel membrane protein, porin, interacted with the TOM and SAM complex protein subunits in a manner similar to $\mathrm{p} 36$. As shown in Figure 7A, the data obtained for $\beta$ ATPase and porin are mostly in accordance with the current working models for the mitochondrial import pathways used by these two proteins $[43-45,51]$. For instance, both $\beta$ ATPase and porin ( $\beta$ ATPase-cVenus and porin-cVenus) interacted with the nVenus-tagged versions of TOM20, TOM22 and mtOM64, reflecting the apparent functional redundancy of these import receptors in plants [52]. Likewise, porin interacted with the N-terminal mutant version of TOM20 (TOM20mut), but $\beta$ ATPase did not, supporting the notion that the import of matrix-destined proteins is dependent primarily on TOM20 via the receptor's $\mathrm{N}$-terminal tetratricopeptide motif domain $[56,58]$. The relative importance of the mtOM64 receptor in $\beta A T P a s e$ and porin (and p36) import using a similar mutagenesis-BiFC approach was not, however, assessed, since deletion of the predicted substrate-receptor binding motif in mtOM64 $[60,70]$ disrupted its sorting to mitochondria in BY-2 cells (data not shown).

Figure 7A shows also that porin, but not $\beta$ ATPase, interacted with METAXIN, consistent with the proposed role of this SAM component in the insertion and assembly of $\beta$ barrel proteins in yeasts, mammals and plants $[47,48,52]$. However, Lister et al. [52] recently showed using pulldown and yeast two-hybrid assays that METAXIN interacted with a number of plant matrix-destined precursor proteins as well as $\beta$-barrel porin and TOM40, suggesting 
that this protein receptor, unlike its counterparts in yeast and mammals, performs a variety of roles in plants in addition to the insertion and assembly of $\beta$-barrel membrane proteins. Other than the use of different experimental approaches in the latter study [52] compared to that employed here, a reason(s) for the apparent lack of interaction between $\beta A T P a s e$ and METAXIN is not known. Regardless, these results for $\beta A T P a s e$ (and p36) and METAXIN, combined with the negative interaction data for certain other protein pairs discussed below (e.g., p36 and $\mathrm{Cb} 5$ ) provides convincing evidence that the Venus fluorescence observed in (positive) BiFC assays (e.g., porin and METAXIN) resulted from specific protein-protein interactions and was not simply a consequence, for example, of the overexpression of protein pairs localized to the same intracellular local (i.e., mitochondrial outer membrane) [65].

At least one unexpected finding from the BiFC experiments presented in Figure 7A was that both $\beta$ ATPase and porin (and p36) did not interact with TOM40, the putative primary subunit of the TOM complex import channel [56]. These results contradict those obtained primarily from studies with yeasts and mammals, wherein TOM40 participates in the import of most types of mitochondrial proteins including those destined for the matrix or outer membrane [43-45]. One possible reason for this apparent lack of interaction between TOM40 and $\beta$ ATPase and porin (and p36) is that this putative channel protein, while being efficiently targeted to mitochondria when expressed individually in BY-2 cells (see Additional file $3 \mathrm{~A}$ ), was not properly inserted/assembled into functional TOM complexes and, thus, could not participate in mitochondrial protein import. Another possible reason may be that the nVenus fragment appended to TOM40 (refer to illustration in Figure 7B) is sterically inaccessible, such that even if the fusion protein was properly assembled into the TOM complex it could not interact with cVenus appended to either co-expressed BATPase, porin or p36. Unfortunately, since another TOM40 fusion protein with nVenus appended to its $\mathrm{C}$ terminus (TOM40-nVenus) was not sorted to mitochondria in BY-2 cells (data not shown) and because no other experimental data has been published for the structure and/or function of a plant TOM40, resolution of this issue remains to be addressed.

In additional control experiments TBSV p33 (p33-cVenus) was not observed to interact with any of the TOM complex subunit proteins tested nor with p36 (Figure 7A). These results were entirely expected since p33 sorts to peroxisomes and not to mitochondria ([25]; see Additional Figure 3A for the localization of p33-cVenus in BY-2 cells). Interactions were also not observed between p36 and porin or $\mathrm{p} 36$ and $\mathrm{Cb} 5$ (Figure 7A), indicating that, similar to the negative results discussed above for $\beta$ ATPase (and p36) and METAXIN, the positive Venus signals detected for certain other protein pairs was due to their specific protein-protein interaction. However, related to these control experiments with $\mathrm{p} 36$, porin and $\mathrm{Cb} 5$, it is important to note that, whereas $\mathrm{Cb} 5$ and $\mathrm{p} 36$ are orientated in outer mitochondrial membranes in an $\mathrm{N}_{\text {out }} \mathrm{C}_{\text {in }}$ [27] and $\mathrm{N}_{\text {out }}-\mathrm{C}_{\text {out }}$ manner (Figure 2; and $[15,18]$ ), respectively, porin contains two putative TMDs and orientated in an $\mathrm{N}_{\text {in }}-\mathrm{C}_{\text {in }}$ manner (Figure 7B; refer also to differential permeabilization results for cVenus-porin in Additional file 3B). Thus, while cVenus appended to porin (porin-cVenus) is predicted to be located in the intermembrane space, nVenus appended to p36 (p36-nVenus) faces the cytosol (Figure 7B) and, thus, the lack of a BiFC signal for these two proteins when co-expressed in BY-2 cells was expected given the physical separation of their corresponding Venus halves [65].

Taken together, the BiFC results presented in Figure 7A indicate that p36 interacts with a variety of import receptors in the TOM complex including TOM20, TOM22, and mtOM64, consistent with recent findings that, compared to yeasts and mammals, the mitochondrial import apparatus in plants is highly flexible with overlapping specificity [52]. Our BiFC results indicate also that whereas the porin interacts with the putative SAM component METAXIN, p36 (and BATPase) does not. Hence, METAXIN appears to participate specifically in the assembly of outer mitochondrial membrane proteins containing a $\beta$-barrel structure, a conclusion that extends the findings presented previously for the role of this mitochondrial import component in plants [52].

\section{Conclusion}

Viruses are well known for their ability to exploit specific organelles and pathways in infected host cells in order to facilitate their replication [1-3]. Here we showed that p36, an essential component of the CIRV replication complex and a key factor involved in the virus' ability to transmogrify mitochondria into MVBs in infected plant cells, contains a prototypic mitochondrial outer membrane targeting signal. That is, similar to the targeting signals characterized for most authentic mitochondrial outer membrane proteins in evolutionarily diverse organisms $[32,33]$, the p36 targeting signal consists of a cluster of positively-charged residues flanked by moderately hydrophobic TMDs. We showed also that p36 interacts with several TOM components, specifically the import receptors TOM20, TOM22 and mtOM64. These results, combined with the apparent conservation of a functional outer mitochondrial targeting signal in p36, indicate that CIRV has evolved a strategy to utilize the host-cell mitochondrial sorting pathways in order to control or modulate the biogenesis and/or function of the organelle to its own advantage. For instance, mitochondrial-derived MVBs in CIRV- 
infected cells could provide the necessary structural framework or platform for replication complex assembly and/ or provide a sophisticated protective structure that shields the nascent viral RNA or viral replication proteins from degradation. Both of these possibilities have been proposed previously for other viruses that also rely on the mitochondrial outer membrane for their replication [7175].

While the functional significance of the CIRV-mitochondria relationship and the molecular mechanisms underlying the membrane rearrangements that occur during mitochondrial MVB biogenesis in CIRV-infected cells remain to be elucidated, future studies aimed at understanding these processes, similar to results presented here for the sorting of $\mathrm{p} 36$, will undoubtedly provide insights to certain aspects of normal mitochondrial biogenesis in plant cells (e.g., membrane remodelling during mitochondria fission). To date, only one plant outer mitochondrial membrane protein, $\mathrm{Cb} 5$, has been well examined in terms of its targeting signal and insertion mechanism [27,76-78]. Thus, as other plant outer mitochondrial membrane proteins begin to be investigated, including those identified using proteomic- and/or bioinformatics-based approaches [79-83], the properties of the p36 targeting signal and its import mechanism will serve as a useful reference.

\section{Methods}

\section{Recombinant DNA procedures and reagents}

Standard recombinant DNA procedures were performed as described by Sambrook et al. [84]. Molecular biology reagents were purchased either from New England BioLabs (Beverly, MA, USA), Promega (Madison, WI, USA), Perkin-Elmer (Perkin-Elmer Biosystems, Mississauga, Canada), Stratagene (La Jolla, CA, USA), or Invitrogen (Carlsbad, CA, USA). Synthetic oligonucleotides were synthesized by either Invitrogen (Frederick, MD) or University of Guelph Laboratory Services (Guelph, Canada); a complete list of the sequences of the oligonucleotides primer used in plasmid constructions described below are provided in Additional file 4. Plasmid DNA was isolated using Qiagen reagents (Qiagen, Mississauga, Canada), and dye terminated cycle sequencing was used with an Applied Biosystems Model 377 or 3730 automated sequencer (Perkin-Elmer Biosystems) to verify all DNA constructs. Mutagenesis was carried out using appropriate complementary forward and reverse mutagenic primers and procedures according to the QuickChange sitedirected mutagenesis kit (Stratagene).

\section{Construction of plasmids}

Plasmids containing $p 36$ and/or p95

pRTL2/p36, encoding the CIRV $36 \mathrm{kDa}$ replicase protein was constructed in the following manner. First, sequences encoding the $\mathrm{p} 36$ ORF were amplified via the polymerase chain reaction (PCR) (primers Fp135 and Rp107; Additional file 4) and the plasmid pUC18/CIRV (purchased from the American Type Culture Collection, clone PVMC47) serving as template DNA. This PCR also introduced a 5' NcoI site and a 3' XmaI site that replaced the p36 stop codon. The resulting PCR products were ligated into pCR2.1 TOPO (Invitrogen) followed by ligation of the NcoI-XmaI fragment from the resulting plasmid (pCR2.1 TOPO/p36-XmaI) into NcoI-XmaI-digested pRTL2, a plant expression vector containing the Cauliflower Mosaic Virus (CaMV) 35S promoter and terminator and the tobacco etch potyvirus leader sequence for enhanced translation [85]. Next, a stop codon was introduced via PCR sitedirected mutagenesis (primers Fp447 and Rp448) at the 3' end of the p36 ORF in pRTL2/p36-XmaI, yielding pRTL2/ p36.

The C-terminal myc-epitope-tagged version of p36 in pRTL2 (pRTL2/p36-myc) was constructed by annealing complementary oligonucleotides (Fp177 and Rp178) that encoded the myc-epitope tag (-EQKLISEEDL-; [22]), a stop codon and $\mathrm{XmaI}$ overhangs, then ligating these into XmaI-digested pRTL2/p36-XmaI. An N-terminal mycepitope-tagged version of p36 (pRTL2/myc-p36) was constructed by annealing complementary oligonucleotides (Fp29 and Rp30) encoding a start codon, the myc epitope and NcoI overhangs, and then ligating these into NcoIdigested pRTL2/p36.

To construct pRTL2/Rep, sequences encoding both CIRV replicase proteins (p36 and p95) were amplified via PCR (primers Fp135 and Rp572) from pUC18/CIRV with 5' $\mathrm{NcoI}$ and 3' XmaI sites. The resulting PCR products were digested with $\mathrm{NcoI}$ and $\mathrm{XmaI}$ and ligated into NcoI-XmaIdigested pRTL2, yielding pRTL2/Rep. pRTL2/p95 was generated by mutating via site-directed mutagenesis (primers Fp642 and Rp641) the p36 amber stop codon at nucleotide positions 1067-1069 to a tyrosine.

An infectious CDNA of CIRV, whereby the sequence for the entire CIRV genome [8] was cloned between a $5^{\prime}$ CaMV 35S promoter and 3' hepatitis delta virus ribozyme, was constructed in three steps. First, a unique StuI site was introduced via site-directed mutagenesis (primers Fp646 and Rp645) upstream of the TBSV sequence in the plasmid pHST20 [86], yielding pHST20/StuI-XmaI. Digestion of this plasmid with StuI and XmaI allowed for the removal of sequences coding for the entire TBSV genome. Second, sequences consisting of the first 621 nucleotides of the CIRV genome were amplified via PCR (primers Fp735 and Rp734 and pUC18/CIRV as template DNA) along with a 5' StuI site. The resulting PCR products were then digested with $S t u I$ and SphI by taking advantage of a unique SphI site within the amplified region of the CIRV 
genome. Third, the remaining sequences for the CIRV genome (nucleotides 622 to 4760) were excised from pUC18/CIRV with SphI and XmaI and then this fragment and the StuI-SphI fragment were ligated together into StuI/ XmaI-digested pHST20/StuI-XmaI, yielding pHST/CIRV.

\section{Plasmids containing p36-CAT or p36-GFP fusion constructs} Construction of p36-CAT fusion constructs was carried out by first introducing various silent restriction sites at specific localizations within the p36 ORF. For instance, a silent MluI site was introduced via PCR site-directed mutagenesis (primers Fp275 and Rp276) at the 3' end of the first TMD in the p36 ORF (amino acid residues 119 and $120)$ to yield pRTL2/p36-myc (MluI). In a second mutagenesis reaction (primers Fp277 and Rp278) a silent AvrII site was introduced immediately after the second TMD in the p36 ORF (amino acid residues 189 and 190) in the plasmid pRTL2/p36-myc (MluI), yielding pRTL2/p36myc (MluI/AvrII).

To construct pRTL2/p36-CAT, encoding the entire p36 ORF fused to the $\mathrm{N}$ terminus of CAT, the Xmal site in pRTL2/p36-XmaI was replaced via site-directed mutagenesis (primers Fp340 and Rp341) with an AvrII site to yield pRTL2/p36-AvrII. Next, the p36 ORF was excised from pRTL2/p36-AvrII with $\mathrm{NcoI}$ and AvrII and ligated into NcoI/AvrII-digested pRTL2/NcoI/MluI/AvrII-CAT. pRTL2/ $\mathrm{NcoI} / \mathrm{MluI} /$ AvrII-CAT is a general purpose cassette vector containing the CAT ORF (minus a start codon) and a convenient 5 ' multiple cloning site (MCS) including in-frame NcoI, MluI and AvrII sites [25]. pRTL2/p36 1-190-CAT, encoding the $\mathrm{N}$-terminal 190 residues from $\mathrm{p} 36$ fused to the N-terminus of CAT, was generated by digesting pRTL2/p36-myc (MluI/AvrII) with NcoI and AvrII and ligating the resulting fragment into NcoI-AvrII-digested pRTL2/NcoI/MluI/AvrII-CAT. To generate pRTL2/p36 1120-CAT, the CAT ORF was excised from pRTL2/MluI/ AvrII-CAT (a modified version of pRTL2/NcoI/MluI/AvrIICAT lacking the unique NcoI site in the MCS; [25]) with MluI and XbaI (located immediately 3' of the CAT ORF) and the resulting fragment was ligated into $M l u \mathrm{I} / X b a \mathrm{I}-$ digested pRTL2/p36-myc (MluI/AvrII). pRTL2/p36 120190-CAT was constructed by first replacing via sitedirected mutagenesis (primers Fp331 and Rp332) the MluI site in pRTL2/p36-myc (MluI/AvrII) with NcoI to yield pRTL2/p36-myc (MluI $\Delta$ NcoI/AvrII). pRTL2/p36-myc (MluI $\Delta$ NcoI/AvrII) was then digested with NcoI and AvrII and the resulting fragment corresponding to a start codon and amino acids 120 to 190 in the p36 ORF was ligated into NcoI/AvrII-digested pRTL2/NcoI/MluI/AvrII-CAT. pRTL2/p36 120-190-CAT was then used a template DNA in a site-directed mutagenesis reaction (primers Fp407 and Rp408) to delete sequences encoding amino acids 166 to 190 in the p36 ORF and corresponding to the p36 TMD2, yielding pRTL2/p36 120-164-CAT. pRTL2/p36 90-
164-CAT and pRTL2/p36 90-190-CAT were constructed by amplifying via PCR (primers Fp449 and Rp453, and Fp457 and Rp453-2, respectively), along with pRTL2/p36myc (MluI $\Delta$ NcoI/AvrII) as template DNA, sequences coding for either amino acids 90 to 164 or 90 to 190 in the p36 ORF along with 5' NcoI and 3' AvrII sites. Next, the PCR products were digested with NcoI and AvrII and ligated into NcoI/AvrII-digested pRTL2/NcoI/MluI/AvrIICAT.

\section{Plasmids containing modified versions of $p 36$ or $p 33$}

pRTL2/p33 1-156-p36-myc, pRTL2/p33 103-156-p36myc and pRTL2/p33 103-131-p36-myc, consisting of p33 amino acids 1 to 156,103 to 156 , and 103 to 131 , respectively, within the context of p36-myc, were constructed as follows. pRTL2/p33 1-156-p36-myc was constructed by digesting pRTL2/p33-myc (MluI) with NcoI and AvrII and ligating the resulting fragment into NcoI/AvrII-digested pRTL2/p36-myc (MluI/AvrII). pRTL2/p33-myc (MluI) is a modified version of pRTL2/p33-myc [25] in which codons 104 and 105 in the p33 ORF were replaced via PCR site-directed mutagenesis (primers Fp273 and Rp274) with a silent MluI site. pRTL2/p33 103-120-p36myc was constructed by digesting pRTL2/p33-myc (MluI) with $M l u I$ and AvrII and ligating the resulting fragment into MluI/AvrII-digested pRTL2/p36-myc (MluI/AvrII). pRTL2/p33 103-131-p36-myc was constructed in two steps. First, annealed complementary oligonucleotides (Fp1983 and Rp1984) encoding amino acids 103-131 from p33 along with 5' MluI and 3' SalI overhangs were ligated into MluI-SalI-digested pRTL2/p36-myc (MluI/ SalI/AvrII), yielding pRTL2/p33 103-131-VDMSAR-p36myc. Second, sequences encoding the remaining p36 amino acids -VDMSAR- at the 3 ' end of the loop sequence in pRTL2/p33 103-131-VDMSAR-p36-myc were removed using site-directed mutagenesis (primers Fp2007 and Rp2008). pRTL2/p36-myc (MluI/SalI/AvrII) was generated by introducing a silent SalI site via site-directed mutagenesis (primers Fp576 and Rp575) upstream of TMD2 in the p36 ORF in pRTL2/p36-myc (MluI/AvrII).

pRTL2/p36 1-190-p33-myc, pRTL2/p36 1-120-p33-myc, and pRTL2/p36 120-190-p33-myc, consisting of p36 amino acids 1 to 190,1 to 120 , and 120 to 190 , respectively, within the context of p33-myc, were constructed as follows. pRTL2/p36 1-190-p33-myc was constructed by digesting pRTL2/p36-myc (MluI/AvrII) with NcoI and AvrII and ligating the resulting fragment into NcoI/AvrIIdigested pRTL2/p33-myc (MluI). pRTL2/p36 1-120-p33myc was constructed by digesting pRTL2/p36-myc (MluI/ AvrII) with $N c o$ I and MluI and ligating the fragment into NcoI/MluI-digested pRTL2/p33-myc (MluI). pRTL2/p36 120-190-p33-myc was constructed by digesting pRTL2/ p36-myc (MluI/AvrII) with MluI and AvrII and ligating the 
fragment into MluI/AvrII-digested pRTL2/p33-myc (MluI).

Plasmids encoding modified versions of p36-myc in which TMD1 and TMD2 were either swapped or replaced (individually or together) with synthetic TMDs were generated as follows. pRTL2/p36-myc TMD1 $\Leftrightarrow$ TMD2, in which TMD1 of p36 was replaced with TMD2 of p36 and vice versa, was constructed by first ligating annealed, complementary synthetic oligonucleotides (Fp654 and Rp653) coding for p36 TMD2 (amino acids 166-188) along with 5' SnaBI and 3' MluI overhangs into SnaBI/ MluI-digested pRTL2/p36-myc (SnaBI/MluI/AvrII), yielding pRTL2/p36-myc TMD1 TMD1 $\triangle \mathrm{TMD} 2$ was then used as template DNA to introduce via site-directed mutagenesis (primers Fp576 and Rp575) a silent Sall site upstream of TMD2 in the p36 ORF, yielding pRTL2/p36-myc TMD1 $\Delta$ TMD2-SalI. Next, two sets of synthetic complementary oligonucleotides (Fp682 and Rp680, and Fp681 and Rp679) coding for TMD1 of p36 along with 5'SalI and 3' AvrII overhangs were annealed and ligated into SalI/AvrII-digested pRTL2/ p36-myc TMD1 TMD1 $\Leftrightarrow$ TMD2.

pRTL2/p36-myc TMD1 $\Delta$ synTMD and pRTL2/p36-myc TMD2 $\Delta$ synTMD, in which TMD1 and TMD2 of p36, respectively, were replaced with an artificial/idealized TMD consisting of multiple -LALV-amino acid repeats [29], were constructed in the following manner. Synthetic complementary oligonucleotides coding for synthetic TMDs of the same length as predicted for p36 TMD1 (18 residues) or TMD2 (23 residues), along with either 5' SnaBI and 3' MluI overhangs (Fp1670 and Rp1672) or 5' SalI and 3' AvrII overhangs (Fp1674 and Rp1675), were annealed and ligated into either SnaBI/MluI-digested pRTL2/p36-myc (SnaBI/MluI/AvrII) or SalI/AvrII-digested pRTL2/p36-myc (MluI/SalI/AvrII). To construct pRTL2/ p36-myc TMD1/TMD2 $\Delta$ synTMD, in which both p36 TMDs were replaced with the artificial/idealized TMDs composed of -LALV-repeats, pRTL2/p36-myc TMD2 $\Delta$ synTMD was digested with $X b a \mathrm{I}$ and the resulting fragment ligated into XbaI-digested pRTL2/p36-myc TMD1 1 synTMD.

pRTL2/p36-myc TMD1 $\Delta$ Cb5TMD was constructed by ligating annealed complementary oligonucleotides (Fp1977 and Rp1978) coding for the 18 amino-acid-long TMD of the tung mitochondrial isoform of Cb5 (isoform D) [27] with 5' SnaBI and 3' MluI overhangs into SnaBIMluI-digested pRTL2/p36-myc (SnaBI/MluI/AvrII). Similarly, pRTL2/p36-myc TMD2 $\triangle$ Cb5TMD was constructed by ligating annealed complementary oligonucleotides (Fp1979 and Rp1980) coding for the p36 amino acid sequence -VDMSARG-immediately adjacent (upstream) to TMD2 and the tung Cb5 TMD into Sall-AvrII-digested pRTL2/p36-myc (MluI/SalI/AvrII). pRTL2/myc-Cb5 $\Delta$ p36 TMD1 and pRTL2/myc-Cb5 $\Delta$ p36 TMD2 encoding an Nterminal myc-tagged version of tung mitochondrial Cb5 with its single C-terminal TMD replaced with either TMD1 or TMD2 from p36 were constructed by ligating annealed complementary oligonucleotides coding for either the p36 TMD1 (Fp1960 and Rp1961) or p36 TMD2 (Fp1962 and Rp1963) and the Cb5 C-terminal hydrophilic (tail) sequence -RKK-COOH, along with a stop codon and $5^{\prime}$ NheI and 3' XbaI overhangs into NheI-XbaI-digested pRTL2/myc-Cb5. Details on the construction of pRTL2/ myc-Cb5 have been published elsewhere [27].

pRTL2/p36-myc TMD1 $\Delta$ p33TMD was constructed by ligating annealed complementary oligonucleotides (Fp113 and Rp114) coding for the p33 TMD1 (residues 84-98) and the amino acid sequence -SYA-immediately downstream of TMD1 with 5' SnaBI and 3' MluI overhangs into SnaBI-MluI-digested pRTL2/p36-myc (SnaBI/ MluI/AvrII). Similarly, pRTL2/p36-myc TMD2 $\Delta$ p33TMD2 was constructed by ligating two sets of annealed complementary oligonucleotides (Fp130A and Rp131A and Fp130B and Rp130B) coding for the p33 TMD2 (residues 132-156) with 5' SalI and 3' AvrII overhangs into SalIAvrII-digested pRTL2/p36-myc (MluI/SalI/AvrII).

pRTL2/p36-myc $\Delta$ 131-157 coding for p36-myc lacking amino acids residues 131-157 within the intervening loop sequence was generated using site-directed mutagenesis (primers Fp1966 and Rp1967), along with pRLT2/ p36-myc as template DNA. pRTL2/p36-myc $\mathrm{K}_{93} \mathrm{~K}_{94} \mathrm{R}_{98} \mathrm{R}_{101} \Delta \mathrm{G}$ in which the positively-charged amino acid residues at positions 93, 94, 98 and 101 in the p36 ORF were each replaced with a glycine were constructed using site-directed mutagenesis (primers Fp412 and Rp410), along with pRTL2/p36-myc as template DNA. pRTL2/p36-myc $\mathrm{K}_{134} \mathrm{~K}_{137} \mathrm{R}_{144} \mathrm{~K}_{151} \Delta \mathrm{G}$ was constructed in two steps. First, sequences encoding arginine at position 144 and lysine at position 151 in p36-myc (pRTL2/p36myc) were mutated to glycines using site-directed mutagenesis (primers Fp2048 and Rp2049), yielding pRTL2/ p36-myc $\mathrm{R}_{144} \mathrm{~K}_{151} \Delta \mathrm{G}$. Second, sequences encoding the lysines at positions 134 and 137 in pRTL2/p36-myc $\mathrm{R}_{144} \mathrm{~K}_{151} \Delta \mathrm{G}$ were mutated to glycines using site-directed mutagenesis (primers Fp2098 and Rp2099), yielding pRTL2/p36-myc $\mathrm{K}_{134} \mathrm{~K}_{137} \mathrm{R}_{144} \mathrm{~K}_{151} \Delta \mathrm{G}$.

\section{Plasmids used for BiFC}

BiFC plasmids used in this study contained fragments derived from Venus, a variant of the yellow fluorescent protein (YFP) [62], and were constructed by replacing sequences encoding the $\mathrm{N}$ - or C-terminal fragments from YFP in the pSATN BiFC series of vectors [63] with sequences encoding the corresponding Venus N-terminal 
(nVenus) or C-terminal (cVenus) fragments. Venus was selected as the fluorescent protein for these redesigned BiFC plasmids because, compared to YFP, it does not require preincubation of cells at lower temperatures to facilitate efficient chromophore maturation [87]. Moreover, Venus is brighter than YFP, thus requiring lower amounts of plasmid(s) for transformations and a shorter incubation time, features that increase both the BiFC signal and specificity in terms of protein-protein interactions [64]. Overall, four different pSATN-based Venus BiFC vectors containing either nVenus or cVenus, an adjacent mycor HA-epitope tag [22] serving as convenient means to immunodistinguish each (co-)expressed fusion protein, and a 5' or 3' MCS for cloning of the test gene were generated, including: pSAT4/nVenus C1, pSAT4/nVenus N1, pSAT4/cVenus C1 and pSAT4/cVenus N1. Details on the construction of these plasmids are as follows.

To construct pSAT4/nVenus C1, sequences encoding the $\mathrm{N}$-terminal 174 amino acids of Venus along with introduced 5' NcoI and 3' BglII sites were amplified via PCR (primers Fp1905 and Rp1922) from pVenus-N1. The PCR products were digested with NcoI-BglII and ligated into NcoI-BglII-digested pSAT4-nEYFP-C1 [63] and the resulting plasmid was digested with BglII and SacI and ligated with annealed complementary oligonucleotides (Fp1941 and Rp1946) coding for the myc epitope along with 5' BglII and 3' SacI overhangs, yielding pSAT4/nVenus C1. pVenus-N1 (provided by Peter Kim, NIH) was constructed by disrupting (via site-directed mutagenesis) the Venus dimerization domain in pVenus-N1-NPY [62] (Nagai et al., 2002) and then cloning the resulting modified Venus gene into pEGFP-N1 (Clontech) lacking the GFP ORF. To construct pSAT4/nVenus $\mathrm{N} 1$, sequences encoding the $\mathrm{N}$ terminal 174 amino acids of Venus, along with an introduced stop codon and 5' BamHI and 3' XbaI sites, were amplified via PCR (primers Fp1909 and Rp1924) from pVenus-N1. PCR products were then digested with BamHI and $\mathrm{XbaI}$ and ligated into BamHI-XbaI-digested pSAT4AnEYFP-N1 [63] that was isolated from dam-E. coli due to dam methylation of the XbaI site in the plasmid's MCS. The resulting plasmid was then digested with SacII and BamHI and ligated with annealed complementary oligonucleotides (Fp1943 and Rp1944) coding for the myc epitope along with 5' SacII and 3' BamHI overhangs, yielding pSAT4/nVenus N1. pSAT4/cVenus C1 was generated by amplifying via PCR (primers Fp1907 and Rp1908 and pVenus-N1 as template DNA) sequences encoding for the C-terminal 65 amino acids (residues 175-239) of Venus, along with a start codon and 5' NcoI and 3' BglII sites. PCR products were digested with $\mathrm{NcoI}$ and $\mathrm{BglII}$ and ligated into NcoI-BglII-digested pSAT2-cEYFP-C1-B [63]. The resulting plasmid was then digested with BglII and SacI and ligated with annealed complementary oligonucleotides (Fp1942 and Rp1947) coding for the HA eptitope tag, along with 5' BglII and 3' SacI overhangs, yielding pSAT4/cVenus C1. pSAT4/cVenus N1 was generated by amplifying via PCR (primers Fp1911 and Rp1912) sequences encoding the C-terminal 65 amino acids and stop codon of Venus, along with introduced $5^{\prime} \mathrm{BamHI}$ and 3' XbaI sites. PCR products were then digested with BamHI and $X b a \mathrm{I}$ and ligated into dam- BamHI-XbaI-digested pSAT4A-CEYFP-N1 [63]. The resulting plasmid was digested with SacII and BamHI and ligated with annealed complementary oligonucleotides (Fp1945 and Rp1948) coding for the HA epitope along with $5^{\prime}$ SacII and 3' BamHI overhangs, yielding pSAT4/cVenus N1.

Construction of BiFC plasmids containing TOM20 (or the mutant version thereof; TOM20mut), TOM22, TOM40 or METAXIN fused at their $\mathrm{N}$ termini to nVenus was carried out as follows. First, sequences encoding the entire TOM20, TOM22, TOM40 or METAXIN ORFs were amplified via PCR using the appropriate oligonucleotide primers (Additional file 4). Plasmids used as template DNA in these PCRs included pRTL2/myc-TOM20-III (provided by P. Dhanoa, University of Guelph), encoding a N-terminal myc-tagged version of Arabidopsis TOM20 isoform III, pSPORT1/TOM22-I (ABRC, clone U83367), encoding isoform I of Arabidopsis TOM22, pUNI51/TOM40-I (ABRC, clone U11102), encoding isoform I of Arabidopsis TOM40, and pUNI51/METAXIN (ABRC, clone U2140), encoding Arabidopsis METAXIN. All PCRs also introduced 5' EcoRI and 3' XmaI sites. Resulting PCR products were then digested with EcoRI and XmaI and fragments were ligated into EcoRI-XmaI-digested pSAT4/ nVenus C1, yielding pSAT4/nVenus-TOM20, pSAT4/nVenus-TOM22, pSAT4/nVenus-TOM40 and pSAT4/nVenusMETAXIN. pSAT4/nVenus-TOM20mut was generated by removing, via site-directed mutagenesis (primers Fp2274 and Rp2275), sequences encoding the first 142 amino acid residues of TOM20 in pSAT4/nVenus-TOM20. This $\mathrm{N}$-terminal region of TOM20 contains a tetratricopeptide motif-based receptor domain proposed to interact with mitochondrial presequences [58].

To construct BiFC plasmids containing p36 fused at its C terminus to nVenus, sequences encoding the entire p36 ORF was amplified via PCR using the appropriate oligonucleotide primers (Additional file 4) and pRTL2/p36myc as template DNA. The PCR also introduced 5' EcoRI and 3' XmaI sites. Resulting PCR products were then digested with EcoRI and XmaI and fragments were ligated into EcoRI-XmaI-digested pSAT4/nVenus C1, yielding pSAT4/p36-nVenus.

pSAT4/mtOM64-nVenus, consisting of the Arabidopsis mitochondrial outer membrane protein of $64-\mathrm{kD}$ (mtOM64), a protein proposed to function as mitochondrial protein receptor $[60,52]$ and fused at its $C$ terminus 
to nVenus, was constructed in the following manner. Initially, a cDNA encoding mtOM64 was isolated using a reverse-transcription PCR-based cloning procedure. Total RNA was purified from $(50 \mathrm{~mL})$ of 4-day-old Arabidopsis (Arabidopsis thaliana var. Landsberg erecta) suspension-cultured cells using Tri Reagent (Sigma-Aldrich Ltd.) and cDNA was then synthesized using an oligo $(\mathrm{dT})_{18}$ primer and the RevertAid ${ }^{\mathrm{TM}} \mathrm{H}$ Minus First Strand cDNA Synthesis Kit (Fermentas, Burlington, Canada). cDNA was then used as a template in a PCR that included primers (Fp2096 and Rp2097) designed specifically to amplify the entire mtOM64 ORF along with 5' XhoI and 3' XmaI sites. PCR conditions consisted of a 2 min incubation at $94^{\circ} \mathrm{C}$, followed by 35 cycles of $40 \mathrm{sec}$ at $94^{\circ} \mathrm{C}, 40 \mathrm{sec}$ at $55^{\circ} \mathrm{C}$, and $30 \mathrm{sec}$ at $72^{\circ} \mathrm{C}$, and then a 10 -minute extension at $72^{\circ} \mathrm{C}$. PCR products were ligated into pCR2.1 TOPO, yielding pCR2.1 TOPO/mtOM64. Next, the XhoI-XmaI fragments from pCR2.1 TOPO/mtOM64 was ligated into XhoI-XmaI-digested pSAT4/nVenus C1, yielding pSAT4/ mtOM64-nVenus.

Construction of BiFC plasmids containing the $\beta$ ATPase presequence, porin, $\mathrm{p} 36$, or $\mathrm{p} 33$ fused at their $\mathrm{C}$ termini to cVenus was carried out as follows. Sequences encoding either the $\beta A T P a s e$ mitochondrial targeting presequence or the entire ORF of porin, p36 or p33 were amplified via PCR using the appropriate oligonucleotide primers (Additional file 4). Plasmids used as template DNA in these PCRs included pUC18/ßATPase-GFP (see below 'Other plasmids'), pUNI51/porin (ABRC, clone U12693) encoding the Arabidopsis porin (also referred to as voltagedependent anion-selective channel protein 1), pRTL2/ p36-myc, and pRTL2/myc-p33 [25]. PCRs with plasmids encoding porin, p36 and p33 also introduced a 5' EcoRI site and a 3' XmaI site that removed each protein's stop codon, whereas PCR with $\beta$ ATPase presequence-containing plasmid DNA introduced 5' and 3' BamHI sites. Resulting PCR products were then digested with EcoRI and $X m a I$ or BamHI and fragments were ligated into EcoRIXmaI- or BamHI-digested pSAT4/cVenus N1, yielding pSAT4/ßATPase-cVenus, pSAT4/porin-cVenus, pSAT4/ p36-cVenus and pSAT4/p33-cVenus. To construct pSAT4/ cVenus-Cb5 consisting of the mitochondrial isoform (isoform D) of tung Cb5 [27] fused at its $\mathrm{N}$ terminus to cVenus, the entire ORF of Cb5 along with 5' EcoRI and 3' XbaI sites was amplified by PCR (primers Fp497 and Rp380) from pRTL2/myc- $\Delta$ NheI Cb5D [27]. PCR products were then digested with EcoRI and XbaI and ligated into EcoRI/ XbaI-digested pSAT4/cVenus C1, yielding pSAT4/cVenusCb5.

\section{Other Plasmids}

pUC18/ßATPase-GFP encoding the N-terminal mitochondrial matrix targeting presequence (residues 1-60) of the $\beta$ subunit of $F_{1}$-ATPase from Nicotiana plumaginfolia fused to the $\mathrm{N}$ terminus of GFP was constructed by amplifying via PCR (primers FpRD1 and RpRD2) the $\beta$ ATPase presequence along with $5^{\prime}$ and $3^{\prime}$ NheI sites, and using pBIN35S 360 catE9 (provided by F. Chaumont, University of Louvain) [66] as the template DNA. The resulting PCR products were then digested with NheI and ligated into NheI-digested pUC18/NheI-GFP, a modified version of pUC18/GFP [88] containing an in-frame NheI site immediately upstream of the GFP ORF. The construction of pRTL2/RFP, also referred to as pRTL2/MCS-RFP-stop, has been described elsewhere [89]. pRTL2/RFP-MFP encoding the RFP fused to the entire ORF of peroxisomal multifunctional protein (MFP) was constructed by ligating the XbaI fragment from pRTL2/GFP-MFP [90] into XbaI-digested pRTL2-RFP-MCS [89].

\section{Transient transformation of tobacco BY-2 cells and fluorescence microscopy}

Tobacco (Nicotiana tabacum cv BY-2) suspension-cultured cells were maintained and prepared for biolistic bombardment as described previously [19]. Briefly, all transient transformations, with the exception of those for BiFC (see below), were performed using tungsten particles coated with $10 \mu \mathrm{g}$ of plasmid DNA (or $5 \mu \mathrm{g}$ of each plasmid for co-transformations) and a biolistic particle delivery system-1000/HE (Bio-Rad Laboratories, Mississauga, Canada). Bombarded cells were incubated for $4 \mathrm{~h}$ to allow for expression and sorting of the introduced gene product(s), then fixed in formaldehyde, incubated with $0.01 \%(\mathrm{w} / \mathrm{v})$ pectolyase Y-23 (Kyowa Chemical Products, Osaka, Japan), and permeabilized with either $0.3 \%(\mathrm{v} / \mathrm{v})$ triton X100 or $25 \mu \mathrm{g} \mathrm{mL}^{-1}$ digitonin (Sigma-Aldrich Ltd.) [26]. Cells were evaluated after $4 \mathrm{~h}$ to ensure that any potential negative effects due to (membrane) protein over-expression were avoided.

Fixed and permeabilized cells were processed for immunofluorescence microscopy as described by Trelease et al. [91]. Primary and dye-conjugated secondary antibodies and sources were as follows: mouse anti-myc antibodies in hybridoma medium (clone 9E10; Princeton University, Monoclonal Antibody Facility, Princeton, NJ, USA); mouse anti-CAT antibodies in hybridoma medium (provided by S. Subramani, University of California, San Diego); rabbit anti-cottonseed catalase IgGs [92]; mouse anti-maize porin [24]; rabbit anti-pea E1 $\beta$ [93]; mouse anti- $\alpha$-tubulin (clone DM 1A) (Sigma-Aldrich Ltd.); rabbit anti-myc and mouse anti-HA (Bethyl Laboratories, Montgomery, TX, USA); rabbit anti-p36 antibodies were raised against a synthetic peptide corresponding to an identical amino acid sequence in both p36 and TBSV p33 (-VEPARELKGKDGEDLLTGSR-) (residues 218-237 in p36 and 184-203 in p33) (refer to the p33 and p36 sequence alignment shown in Figure 4A) [25]; goat antimouse Alexa Fluor 488 IgGs (Cedar Lane Laboratories, 
Ontario, Canada); goat anti-rabbit rhodamine red-X IgGs (Jackson ImmunoResearch Laboratories, West Grove, PA, USA). Concanavalin A conjugated to Alexa 594 (Molecular probes, Eugene, OR) was added to BY-2 cells at a final concentration of $5 \mu \mathrm{g} \mathrm{mL}^{-1}$ during the final $20 \mathrm{~min}$ of incubation with secondary antibodies. All antibodies raised in rabbits were IgG-affinity purified using protein A-Sepharose columns.

Epifluorescent images of BY-2 cells were acquired using a Zeiss Axioskop 2 MOT epifluorescence microscope (Carl Zeiss, Toronto, Canada) with a Zeiss $63 \times$ Plan Apochromat oil-immersion objective. Image captures were performed using a Retiga 1300 charge-coupled device camera (Qimaging, Burnaby, Canada) and Northern Eclipse 5.0 (Empix Imaging, Mississauga, Canada) or OpenLab 5.0 (Improvision Inc., Lexington, MA, USA) software. CLSM images of BY-2 cells were acquired using a Leica DM RBE microscope with a Leica $63 \times$ Plan Apochromat oil-immersion objective, a Leica TCS SP2 scanning head, and the Leica TCS NT software package (Version 2.61) (Leica, Heidelberg, Germany). Fluorophore emissions were collected sequentially in double- and triple-labeling experiments; single-labeling experiments showed no detectable crossover at the settings used for data collection. Confocal images were acquired as a z-series of representative cells and single optical sections were saved as $512 \times 512$-pixel digital images. All fluorescence images of cells shown in individual figures are representative of $>50$ independent (transient) transformations from at least two independent transformation experiments. Figure compositions were generated using Adobe Photoshop CS (Adobe Systems, San Jose, CA).

\section{BiFC}

Biolistic bombardment of cells for BiFC experiments was carried out essentially as described above with the exception that tungsten particles were coated with 200 ng each of plasmids encoding the appropriate combinations of proteins. Tungsten particles were coated also with $200 \mathrm{ng}$ of pRTL2/RFP serving as an internal reference marker to help identify cells that were transformed and, thus, could be examined for the BiFC signal. Alternatively, particles were coated also with $200 \mathrm{ng}$ of pUC18/ßATPase-GFP or pRTL2/RFP-MFP serving as a mitochondrial or peroxisomal marker protein, respectively, and for assessing (mitochondrial or peroxisomal) localization of co-expressed Venus half fusion proteins.

Approximately $16 \mathrm{~h}$ after bombardment, cells were formaldehyde fixed and either examined (via fluorescence microscopy) for BiFC (and RFP) or processed for immunofluorescence microscopy as described above. The $16 \mathrm{~h}$ time point and the amounts of plasmid DNA employed in BiFC assays were chosen based on preliminary optimiza- tion experiments aimed at eliminating the possibility of any non-specific (false positive) reconstitutions that may occur due to protein (over)expression [reviewed in $[94,95]]$. Overall, the conditions used for BiFC were based on those in which nVenus- or nVenus-tagged versions of the various TOM proteins, $\mathrm{p} 36, \mathrm{p} 33$, porin and the $\beta A T$ Pase presequence co-expressed with the corresponding "empty" vector containing the nVenus or cVenus alone yield no significant BiFC (Venus) fluorescence (data not shown). Also, transformations with RFP (or $\beta$ ATPase-GFP or RFP-MFP) alone, confirmed that there was no crossbleed of the red (or green) fluorescence signal into the yellow channel.

Topological orientations of Venus half fusion proteins were determined using digitonin (differential) permeabilization as described above, with the exception that biolistic bombardments were performed with gold particles (Sigma-Aldrich Ltd.) coated with $5 \mu \mathrm{g}$ of plasmid DNA, and cells were formaldehyde fixed $\sim 4 \mathrm{~h}$ after bombardment.

\section{Rub inoculation of C. quinoa and electron microscopy}

Chenopodium quinoa plants were grown in chambers at $21^{\circ} \mathrm{C}$ with a $12 \mathrm{~h}$ light $-12 \mathrm{~h}$ dark cycle and five days prior to rub inoculation plants were transferred to a laboratory bench top with lower light conditions to facilitate the infection process [86]. Rub inoculations (including mock inoculations) were carried out with 6-to-8-leaf stage plants and $10 \mu \mathrm{g}$ of CIRV infectious CDNA diluted in $30 \mu \mathrm{l}$ of inoculation buffer [86]. Approximately 7 to 10 days after inoculations, $\sim 1 \mathrm{~cm}^{2}$ sections of the rub-innoculated leaf, including several necrotic lesions, were removed and processed for electron microscopy.

CIRV cDNA rub-inoculated C. quinoa leaf pieces were processed for transmission electron microscopy (TEM) by fixing in $4 \%(\mathrm{v} / \mathrm{v})$ gluteraldehyde (Fisher Scientific, Markam, Canada) and $1 \%(\mathrm{v} / \mathrm{v})$ acrolein (Sigma-Aldrich Ltd.) in $0.025 \mathrm{M} \mathrm{NaKPO}_{4}$ buffer (pH 7.2) for $2 \mathrm{~h}$ in a vacuum chamber and then at $4{ }^{\circ} \mathrm{C}$ overnight. Samples were then washed three times in $0.025 \mathrm{M} \mathrm{NaKPO}_{4}$ buffer at $2 \mathrm{~h}$ intervals and $4{ }^{\circ} \mathrm{C}$, then post-fixed overnight at $4{ }^{\circ} \mathrm{C}$ in $1 \%$ $(\mathrm{w} / \mathrm{v})$ osmium tetroxide (Fisher Scientific), dehydrated in a graded series of ethanol (50 to $100 \%$ [v/v]), and embedded in Spurr's medium-grade epoxy [96]. Thin sections were cut with a glass or diamond knife, mounted on copper grids and post-stained with $2 \%(\mathrm{w} / \mathrm{v})$ uranyl acetate and Reynold's lead citrate [97] for 10 and 3 min, respectively. All images were acquired at $80 \mathrm{kV}$ with a Phillips (Mahwah, NJ, USA) CM10 TEM.

\section{Accession numbers}

National Center for Biotechnology Information (NCBI) and/or Arabidopsis Genome Initiative (AGI) database 
accession numbers for proteins described in this study are as follows: $\beta$ ATPase (P17614), Cb5D (AAT84461), CIRV p36 (CAA59477), CIRV p95 (NP_612580), METAXIN (NP_565446, At2g19080), MFP (AAL35606), mtOM64 (NP_196504; At5g09420), porin (Q9SRH5; At3g01280), TBSV p33 (NP_062898), TOM20 (NP_189344; At3g27080), TOM22 (NP_563699; At1g04070), TOM40 (NP_188634; At3g2000).

\section{Abbreviations}

$\beta$ ATPase: $\beta$ subunit of the $\mathrm{F}_{1}$-ATPase; BiFC: bimolecular fluorescence complementation; BY-2: Bright Yellow-2; CAT: chloramphenicol acetyltransferase; Cb5: cytochrome $b_{5}$; CIRV: Carnation Italian ringspot virus; ConA: Concanavalin A; CLSM: confocal laser-scanning microscopy; CaMV: Cauliflower Mosaic Virus; cVenus: C-terminal half of Venus; CymRSV: Cymbidium ringspot virus; E1 $\beta$ : $\beta$ subunit of the mitochondrial pyruvate dehydrogenase complex; ER: endoplasmic reticulum; FIS1: protein, fission 1; Fzo1: fuzzy onion 1; GFP: green fluorescent protein; HA: hemaglutinin; kD: kilodalton; MCS: multiple cloning site; Mfn: mitofusin; MFP: multifunctional protein; mtOM64: mitochondrial outer membrane protein of 64-kD; MVB: multivesicular body; ORF: open reading frame; pER: peroxisomal ER; PCR: polymerase chain reaction; FIS1: protein fission 1; nVenus: N-terminal half of Venus; p33: 33-kD membrane-bound replication protein; p36: 36-kD RNA-binding protein; p92: 92-kD RNAdependent RNA polymerase; p95: 95-kD RNA-dependent RNA polymerase; RFP: red fluorescent protein; SAM: sorting and assembly machinery; TBSV: Tomato bushy stunt virus; TEM: transmission electron microscopy; TIM: translocase of the inner mitochondrial membrane; TOM: translocase complex in the mitochondrial outer membrane; TMD: transmembrane domain; YFP: yellow fluorescent protein.

\section{Authors' contributions}

YTH, AWM and SKG conducted the experiments. YTH, AWM and RTM designed and planned the experiments, YTH and RTM were involved in writing the paper, and all authors read, provided critical comments, and approved the final manuscript.

\section{Acknowledgements}

The authors thank Jan Mierynk (University of Missouri-Columbia) for anti-E1b antibodies, Tom Elthon (University of Nebraska-Lincoln) for anti-porin antibodies, Stanton Gelvin (Purdue University) for pSATN BiFC plasmids, Scott Bingham (Arizona State University) for assistance with sequencing, and John Greenwood (University of Guelph) for guidance with electron microscopy. We also thank Kimberley Gibson and Graham Smith for cell culture maintenance, Ian Smith for assistance with designing Figure 7B, and Baozhong Meng, Preetinder Dhanoa and Rosa Di Leo (University of Guelph) for C. quinoa seeds, pRTL2/myc-TOM20-III, and pUC18/bATPase-GFP, respectively. Financial support for S.K.G. was generously provided by Steven Rothstein (University of Guelph) with funds from the Ontario Research and
Development Challenge Fund (Ontario Centre for Agriculture Genomics) (grant no. 046061 to S.R.). This work was supported by a grant from the Natural Sciences and Engineering Research Council of Canada (NSERC) (grant no. 21729I to R.T.M.).

\section{Additional material}

\section{Additional file 1}

Localization of $p 36$ expressed alone or together with the p95 replication protein in BY-2 cells and electron microscopic analysis of Chenopodium quinoa meosphyll cells transformed with CIRV. (A) Tobacco BY-2 cells were transformed transiently (via biolistic bombardment) with $p 36$ either alone, together with the other CIRV replication protein $p 95$ (Rep), or in the context of full-length infectious CIRV (CIRV cDNA). Cells were then processed for immunofluorescence CLSM with expressed $p 36$ and $p 95$ being immunodetected using primary antibodies raised against a synthetic peptide that corresponds to an amino acid sequence in both $p 36$ and $p 95$ [25]. As mentioned in the 'Introduction', p95 is produced by the translational read-through of the $p 36$ amber stop codon [7]. Hatched boxes represent the portion of the cells shown at higher magnification in the panels to the right. The yellow/orange color in the merge images indicate co-localization of expressed p36 (and p95) and the endogenous outer mitochondrial membrane protein porin; arrowheads also indicate obvious co-localizations. Bar $=10 \mu \mathrm{m}$. (B) Individual C. quinoa leaves rub-inoculated with an infectious CIRV cDNA (see 'Methods and Materials' for details) or mock rub-inoculated at 7 days post inoculation. Arrowheads indicate examples of necrotic lesions on the surface of the CIRV-infected leaf; necrotic lesions were not observed on leaves of mock rub-inoculated plants. Bar $=2 \mathrm{~cm}$. (C) Representative transmission electron micrographs of a mitochondria-derived MVB and wild-type mitochondrion in mesophyll cells of $\mathrm{C}$. quinoa leaves rub-inoculated with the infectious CDNA of CIRV and mock rub-inoculated, respectively. Arrowheads denote examples of distinct vesicle/spherule-like structures located in the intermembrane space of the mitochondria-derived MVB that are proposed to be derived by invaginations of the outer mitochondrial membrane and serve as the sites for CIRV RNA replication [13,4]. Note also that the cristae are significantly altered (and less in number) in the mitochondria-derived MVB of the CIRV-transformed cell; compare with morphology of the cristae in the mitochondria of the mock-transformed cell. $C W$, cell wall; Cyt, cytosol; Mito, mitochondria; $m M V B$, mitochondriaderived multivesicular body; Vac, vacuole. Bars $=0.5 \mu \mathrm{m}$.

Click here for file

[http://www.biomedcentral.com/content/supplementary/14712121-9-54-S1.tiff] 


\section{Additional file 2}

Localization of p36-CAT and topological orientation of p36 90-190CAT in BY-2 cells. (A) Tobacco BY-2 cells were transformed transiently (via biolistic bombardment) with $p 36$ 90-190-CAT (consisting of the $p 36$ amino acid residues 90-190 fused to the N-terminus of CAT) and then processed for immunofluorescence CLSM using primary antibodies raised against CAT. Hatched boxes represent the portion of the cells shown at higher magnification in the panels to the right. The merged image shows that the torus fluorescent structures containing p36 90-190-CAT delineate the spherical structures attributable to mitochondrial matrix-localized E1 $\beta$. Arrowheads indicate obvious examples of a toroidal enclosure of a sphere. Bar $=10 \mu \mathrm{m}$. (B) BY-2 cells were transformed transiently (via biolistic bombardment) with $p 36$ 90-190-CAT, fixed, and then permeabilized with either triton X-100 (which permeabilizes both the plasma membrane and organellar membranes) or digitonin (which permeabilizes only the plasma membrane). Permeabilized cells were then processed for (immuno)epifluorescence microscopy using antibodies raised against (as indicated by the labelling at the top left of each micrograph) either cytosolic $\alpha$-tubulin, mitochondrial matrix E1 $\beta$, or CAT (in p36 90-190CAT). Note that, similar to endogenous cytosolic $\alpha$-tubulin, p36 90-190$C A T$, but not endogenous mitochondrial matrix E1 $\beta$, were immunodetected in both triton X-100- and digititon-permeabilized cells, indicating that the C-terminal-appended CAT moiety was exposed to the cytosol. Although the relative position of the $N$ terminus of $p 36$ 90-190-CAT was not directly tested in these differential permeabilization experiments, this fusion protein, similar to full-length $p 36$ (refer to Figure 2), is likely orientated in an $N_{\text {out }}-C_{\text {out }}$ topology. This is because the cytosolic-facing $C$ terminus of p36 90-190-CAT, together with an even number (two) of predicted TMDs, suggests that its $N$ terminus is also exposed to the cytosol. Differential interference contrast (DIC) images correspond to the same cells shown to the left. Bar $=10 \mu \mathrm{m}$.

Click here for file

[http://www.biomedcentral.com/content/supplementary/14712121-9-54-S2.tiff]

\section{Additional file 3}

Localization and topology of nVenus and cVenus fusion proteins used in BiFC assays. (A) Tobacco BY-2 cells were transformed transiently (via biolistic bombardment) with selected individual nVenus (and myctagged) or cVenus (and HA-tagged) fusion proteins as shown in Figures $7 A$ and $7 B$ (refer to Methods 'Construction of plasmids: Plasmids used for BiFC' for details on the cloning of individual Venus half and epitope-tagged fusion proteins). With the exception of cell transformed with p33-cVenus, all cells were also co-transformed with BATPase-GFP, consisting of the N-terminal mitochondrial targeting presequence (residues 1-60) of the $\beta$ ATPase fused to the $N$ terminus of GFP, and serving as a well-established mitochondrial marker protein $[66,67]$, and thus confirming their mitochondrial localization. Cells transformed with $p 33-$ cVenus were co-transformed with RFP-MFP, consisting of the RFP fused to the $N$-terminal end of peroxisomal matrix marker protein MFP serving as a peroxisomal matrix marker protein $[90,99]$. At $~ 16$ h post-bombardment, all cells were then processed for (immuno)epifluorescence microscopy using anti-myc or anti-HA antibodies. Each micrograph is labelled at the top left with the name of the transiently co-expressed fusion protein. Differential interference contrast (DIC) images correspond to the same cells shown to the left. Note that with the exception of peroxisomal-localized p33-cVenus, all individual nVenus and cVenus fusion proteins sorted to mitochondria as evidenced by their co-localization with $\beta A T P a s e-G F P$. p33-cVenus, on the other hand, colocalized with RFP-MFP, as expected for this peroxisomal-localized viral protein [25]. Bar $=10 \mu \mathrm{m}$. (B) BY-2 cells were transformed with various individual nVenus (and myc-tagged) or cVenus (and HA-tagged) fusion proteins as in (A); however, cells were incubated with digitonin (rather than triton $X-100$ as in [A]) which permeabilizes only the plasma membrane and not organellar membranes [26]. Permeabilized cells were then processed for immuno(epi)fluorescence microscopy using anti-myc, anti-HA, anti-E1 $\beta$, anti- $\beta$ ATPase and/ or anti- $\alpha$-tubulin antibodies. Each micrograph is labelled at the top left with the name of the transiently-expressed fusion protein or endogenous E1 $\beta, \beta$ ATPase or $\alpha$-tubulin. Note that the presence or absence of an immunofluorescence signal attributable to an expressed fusion protein indicates whether or not the protein's appended myc- or HA-epitope tag (immediately adjacent to nVenus or cVenus, respectively) is exposed to the cytosol or not; compare to the absence or presence of an immunofluorescence signal attributable to mitochondrial matrix-localized E1 $\beta$ or cytosolic $\alpha$-tubulin in the same cells. Note also that the relative position of the myc-or HA-epitope tag (and the immediately adjacent $n V e n u s$ or cVenus fragment, respectively) for selected fusion proteins localized to the mitochondrial outer membrane are shown in Figure $7 B$ (indicated with asterisks). DIC images correspond to the same cells shown to the left. Bar $=10 \mu \mathrm{m}$

Click here for file

[http://www.biomedcentral.com/content/supplementary/14712121-9-54-S3.tiff]

\section{Additional file 4}

List of synthetic oligonucleotide primers used in the construction of plasmids.

Click here for file

[http://www.biomedcentral.com/content/supplementary/14712121-9-54-S4.pdf]

\section{References}

I. Salonen A, Ahola T, Kääriäinen L: Viral RNA replication in association with cellular membranes. Curr Top Microbiol Immunol 2005, 285: 139-173.

2. Mackenzie ]: Wrapping things up about virus RNA replication. Traffic 2005, 6:967-977. 
3. Novoa RR, Calderita G, Arranz R, Fontana J, Granzow H, Risco C Virus factories: association of cell organelles for viral replication and morphogenesis. Biol Cell 2005, 97: 147-I72.

4. Martelli GP, Gallitelli G, Russo M: The plant viruses: polyhedral virions with monopartite RNA genomes. In Tombuviruses Edited by: Koenig R. Plenum Publishing Corp, New York; 1988: I 3-72.

5. Mullen RT, Gidda SK: The role of peroxisomes in viral replication. In The peroxisome: orchestrating important developmental decisions from inside the cell Edited by: Titorenko VI, Terlecky SR. Research Signpost; 2008 in press.

6. Russo M, Burgyan J, Martelli GP: The molecular biology of Tombusviridae. Adv Virus Res 1994, 44:382-424.

7. White KA, Nagy PD: Advances in the molecular biology of tombusviruses: gene expression, genome replication, and recombination. Prog Nucleic Acid Res Mol Biol 2004, 78: 187-226.

8. Rubino L, Burgyan J, Russo M: Molecular cloning and complete nucleotide sequence of carnation Italian ringspot tombusvirus genomic and defective interfering RNAs. Arch Virol 1995 I 40:2027-2039.

9. Appiano A, Bassi M, D'Agostino G: Cytochemical and autoradiographic observations on tomato bushy stunt virus-induced multivesicular bodies. Ultramicroscopy 1983, I 2: I62.

10. Appiano A, D'Agostino G, Bassi N, Barbieri N, Viale G, Dell'Orto P. Origin and function of tomato bushy stunt virus-induced inclusion bodies. II. Quantitative electron microscope autoradiography and immunogold cytochemistry. J Ultrastruct Res 1986, 97:31-38.

II. Lupo R, Rubino L, Russo M: Immunodetection of the 33K/92K polymerase proteins in cymbidium ringspot virus-infected and in transgenic plant tissue extracts. Arch Virol 1994, 138:135-142.

12. Scholthof KB, Scholthof HB, Jackson AO: The tomato bushy stunt virus replicase proteins are coordinately expressed and membrane associated. Virology 1995, 208(I):365-9.

13. Di Franco A, Russo M, Martelli GP: Ultrastructure and origin of cytoplasmic multivesicular bodies induced by carnation Italian ringspot virus. I Gen Virol 1984, 65: | 233-I 237

14. Burgyan J, Rubino L, Russo M: The 5'-terminal region of a tombusvirus genome determines the origin of multivesicular bodies. J Gen Virol 1995, 77(Pt 8): 1967-74.

15. Rubino $L$, Russo M: Membrane targeting sequences in tombusvirus infections. Virology 1998, 252(2):43।-7.

16. Rubino L, DiFranco A, Russo M: Expression of a plant virus nonstructural protein in Saccharomyces cerevisiae causes membrane proliferation and altered mitochondrial morphology. I Gen Virol 2000, 8I:279-286.

17. Rubino L, Weber-Lofti F, Dietrich A, Stussi-Garaud C, Russo M: The open reading frame I-encoded ('36K') protein of carnation Italian ringspot virus localizes to mitochondria. J Gen Virol 2001, 82:29-34.

18. Weber-Lotfi F, Dietrich A, Russo M, Rubino L: Mitochondrial targeting and membrane anchoring of a viral replicase in plant and yeast cells. J Virol 2002:10485-10496

19. Banjoko A, Trelease RN: Development and application of an in vivo plant peroxisome import system. Plant Physiol 1995 I07(4): 1201-8.

20. Brandizzi F, Irons S, Kearns A, Hawes C: BY-2 cells: culture and transformation for live-cell imaging. Curr Protoc Cell Biol 2003 I(I.7):.

21. Miao YS, Jiang L: Transient expression of fluorescent fusion proteins in protoplasts of suspension cultured cells. Nature Protocols 2007, 2:2348-2353.

22. Fritze CE, Anderson TR: Epitope tagging: general method for tracking recombinant proteins. Methods Enzymol 2000 327:3-16.

23. Luethy MH, David NR, Elthon TE, Mierynk JA, Randall DD: Characterization of a monoclonal antibody directed against the $\mathrm{EI} \alpha$ subunit of plant pyruvate dehydrogenase. J Plant Physiol 1995, | 45:442-449.

24. Blake JA, Lee KW, Morris TJ, Elthon TE: Effects of turnip crinkle virus infection on the structure and function of mitochondria and expression of stress proteins in turnips. Physiol Plant 2007, I 29:698-706.

25. McCartney AW, Greenwood JS, Fabian MR, White KA, Mullen RT: Localization of the tomato bushy stunt virus replication pro- tein p33 reveals a peroxisome-to-endoplasmic reticulum sorting pathway. Plant Cell 2005, I 7:35 I3-353I.

26. Lee MS, Mullen RT, Trelease RN: Oilseed isocitrate lyases lacking their essential type I peroxisomal targeting signal are piggybacked to glyoxysomes. Plant Cell 1997, 9:185-197.

27. Hwang YT, Pelitire SM, Henderson MP, Andrews DW, Dyer JM, Mullen RT: Novel targeting signals mediate the sorting of different isoforms of the tail-anchored membrane protein cytochrome $b_{5}$ to either endoplasmic reticulum or mitochondria. Plant Cell 2004, 16:3002-3019.

28. Kyte J, Doolittle RF: A simple method for displaying the hydropathic character of a protein. I Mol Biol 1982, I 57:105-132.

29. Davis NG, Model P: An artificial anchor domain: hydrophobicity suffices to stop transfer. Cell 1985, 41:607-6I4.

30. Navarro B, Rubino L, Russo M: Expression of the Cymbidium ringspot virus 33-kilodalton protein in Saccharomyces cerevisiae and molecular dissection of the peroxisomal targeting signal. J Virol 2004, 78:4744-4752.

31. Panavas T, Hawkins CM, Panaviene Z, Nagy PD: The role of the p33:p33/p92 interaction domain in RNA replication and intracellular localization of p33 and p92 proteins of cucumber necrosis tombusvirus. Virology 2005, 338(I):8I-95.

32. Rapaport D, Nargang FE: Mitochondrial biogenesis: protein import into and across the outer membrane. Topics Curr Genetics 2004, 8:37-58

33. Walther DM, Rapaport D: Biogenesis of mitochondrial outer membrane proteins. Biochim Biophys Acta in press.

34. Waizenegger T, Stan T, Neupert W, Rapaport D: Signal-anchor domains of proteins of the outer membrane of mitochondria: structural and functional characteristics. I Biol Chem 2003, 278:42064-4207।.

35. Kanaji S, Iwahashi J, Kida Y, Sakaguchi M, Mihara K: Characterization of the signal that directs Tom 20 to the mitochondrial outer membrane. I Cell Biol 2000, I 5 I:277-288.

36. Beilharz T, Egan B, Silver PA, Hofmann K, Lithgow T: Bipartite signals mediate subcellular targeting of tail-anchored membrane proteins in Saccharomyces cerevisiae. J Biol Chem 2003, 278:8219-8223

37. Wattenberg BW, Clark D, Brock S: An artificial mitochondrial tail signal/anchor sequence confirms a requirement for moderate hydrophobicity for targeting. Biosci Rep 2007, 27:385-40 I.

38. Allen R, Egan B, Gabriel K, Beilharz T, Lithgow T: A conserved proline residue is present in the transmembrane-spanning domain of Tom 7 and other tail-anchored protein subunits of the TOM translocase. FEBS Lett 2002, 5 I 4:347-350.

39. Horie C, Suzuki H, Sakaguchi M, Mihara K: Targeting and assembly of mitochondrial tail-anchored protein Tom5 to the TOM complex depend on a signal distinct from that of tailanchored proteins dispersed in the membrane. J Biol Chem 2003, 278:4|462-4|47I.

40. Shore GC, McBride HM, Millar DG, Steenaart NA, Nguyen M: Import and insertion of proteins into the mitochondrial outer membrane. Eur J Biochem 1995, 227:9-18.

4I. Fritz S, Rapaport D, Klanner E, Neupert W, Westermann B: Connection of mitochondrial outer and inner membranes by Fzol is critical for organellar fusion. / Cell Biol 200I:683-692.

42. Rojo M, Legros F, Chateau D, Lombes A: Membrane topology and mitochondrial targeting of mitofusins, ubiquitous mammalian homologs of the transmembrane GTPase Fzo. I Cell Sci 2002, I I 5: I663-1674.

43. Bohnert M, Pfanner N, Laan M Van der: A dynamic machinery for import of mitochondrial precursor proteins. FEBS Lett 2007, 581:2802-2810.

44. Neupert W, Herrmann JM: Translocation of proteins into mitochondria. Annu Rev Biochem 2007, 76:723-749.

45. Bolender N, Sickmann A, Wagner R, Meisinger C, Pfanner N: Multiple pathways for sorting mitochondrial precursor proteins. EMBO Rep 2008, 9:42-49.

46. Otera H, Taira Y, Horie C, Suzuki Y, Suzuki H, Setoguchi K, Kato H, Oka T, Mihara $\mathrm{K}$ : A novel insertion pathway of mitochondrial outer membrane proteins with multiple transmembrane segments. J Cell Biol 2007, I 79: I 355-I363.

47. Stojanovski D, Guiard B, Kozjak-Pavlovic V, Pfanner N, Meisinger C: Alternative function for the mitochondrial SAM complex in biogenesis of $\alpha$-helical TOM proteins. J Cell Biol 2007, 1 79:88|-893. 
48. Paschen SA, Neupert W, Rapaport D: Biogenesis of beta-barrel membrane proteins of mitochondria. Trends Biochem Sci 2005 , 30:575-582.

49. Setoguchi K, Otera H, Mihara K: Cytosolic factor- and TOMindependent import of C-tail-anchored mitochondrial outer membrane proteins. EMBO J 2006, 25:5635-5647.

50. Kemper C, Habib SJ, Engl G, Hechmeyer P, Dimmer KS, Rapaport D: Integration of tail-anchored proteins into the mitochondria outer membrane does not require any known import components. J Cell Sci 2008, I 2 I: 1990-1998.

51. Lister R, Hulette JM, Lithgow T, Whelan J: Protein import into mitochondria: origins and functions today. Mol Mem Biol 2005, 22:87-100

52. Lister R, Carrie C, Duncan O, Ho LH, Howell KA: Functional definition of outer membrane proteins involved in preprotein import into mitochondria. Plant Cell 2007, 19:3739-3759.

53. Mayer A, Lill R, Neupert W: Translocation and insertion of precursor proteins into isolated outer membranes of mitochondria. J Cell Biol 1993, I 2 I: 1233-1243.

54. Mayer A, Nargang FE, Neupert W, Lill R: MOM22 is a receptor for mitochondrial targeting sequences and cooperates with MOM I9. EMBO J I995, I 4:4204-42I I

55. Pfaller R, Pfanner N, Neupert W: Mitochondrial protein import Bypass of proteinaceous surface receptors can occur with low specificity and efficiency. J Biol Chem I989, 264:34-39.

56. Werhahn W, Niemeyer A, Jänsch L, Kruft V, Schmitz UK, Braun H: Purification and characterization of the preprotein translocase of the outer mitochondrial membrane from Arabidopsis. Identification of multiple forms of TOM20. Plant Physio 200I, I 25:943-954.

57. Lister R, Whelan J: Mitochondrial protein import: convergent solutions for receptor structure. Curr Biol 2006, I6:197-199.

58. Perry AJ, Hulett JM, Likic VA, Lithgow T, Gooley PR: Convergent evolution of receptors for protein import into mitochondria. Curr Biol 2006, 16:221-229.

59. Macasev D, Whelan J, Newbigin E, Silva-Filho MC, Mulhern TD, Lithgow T: Tom 22', an 8-kDa trans-site receptor in plants and protozoans, is a conserved feature of the TOM complex that appeared early in the evolution of eukaryotes. Mol Biol Evol 2004, 2 I: 1557-1564

60. Chew O, Lister R, Qbabou S, Heazlewood JL, Soll J, Schleiff E, Millar $\mathrm{AH}$, Whelan J: A plant outer mitochondrial membrane protein with high amino acid sequence identity to a chloroplast protein import receptor. FEBS Lett 2004, 557: 109- I I4.

61. Lister R, Chew O, Lee MN, Heazlewood JL, Clifton R, Parker KL, Millar $\mathrm{AH}$, Whelan J: A transcriptomic and proteomic characterisation of the Arabidopsis mitochondrial protein import apparatus and its response to mitochondrial dysfunction. Plant Physiol 2004, I34:777-789.

62. Nagai T, Ibata K, Park ES, Kubota M, Mikoshiba K, Miyawaki A: A variant of yellow fluorescent protein with fast and efficient maturation for cell-biological applications. Nat Biotechnol 2002 , 20:87-90.

63. Citovsky V, Lee LY, Vyas S, Glick E, Chen MH, Vainstein A, Gafni Y, Gelvin SB, Tzfira T: Subcellular localization of interacting proteins by bimolecular fluorescence complementation in planta. J Mol Biol 2006, 362: | |20-I|3|.

64. Shyu YJ, Liu H, Deng X, Hu CD: Identification of new fluorescent protein fragments for bimolecular fluorescence complementation analysis under physiological conditions. Biotechniques 2006, 40:61-66.

65. Kerppola TK: Bimolecular fluorescence complementation: visualization of molecular interactions in living cells. Methods Cell Biol 2008, 85:431-470.

66. Chaumont F, Silva MD, Thomas D, Leterme S, Boutry M: Truncated presequences of mitochondrial $F_{1}$-ATPase beta-subunit from Nicotiana plumbaginifolia transport CAT and GUS proteins into mitochondria of transgenic tobacco. Plant Mol Biol 1994, 24:63|-64|.

67. Simpson JP, Di Leo R, Dhanoa PK, Allan WL, Makhmoudova A, Clark SM, Hoover GJ, Mullen RT, Shelp BJ: Identification and characterization of a plastid-localized Arabidopsis glyoxylate reductase isoform: comparison with a cytosolic isoform and implications for cellular redox homeostasis and aldehyde detoxification. J Exp Bot 2008, 59:2545-2554.
68. Rajendran KS, Nagy PD: Surface plasmon resonance analysis of interactions between replicase proteins of tomato bushy stunt virus. Methods $\mathrm{Mol} \mathrm{Biol} 2008,45 \mathrm{I}: 55-68$.

69. Pantaleo $\mathrm{V}$, Rubino $\mathrm{L}$, Russo $M$ : The $\mathrm{p} 36$ and $\mathrm{p} 95$ replicase proteins of carnation Italian ringspot virus cooperate in stabilizing defective interfering RNA. J Gen Virol 2004, 85:2429-2433.

70. Chan NC, Likic VA, Waller RF, Mulhern TD, Lithgow T: The C-terminal TPR domain of Tom70 defines a family of mitochondrial protein import receptors found only in animals and fungi. J Mol Biol 2006, 358: 1010-1022.

7I. Miller DJ, Ahlquist P: Flock house virus RNA polymerase is a transmembrane protein with amino-terminal sequences sufficient for mitochondrial localization and membrane insertion. J Virol 2002, 76(19):9856-67.

72. Guo YX, Chan SW, Kwang J: Membrane association of greasy grouper nervous necrosis virus protein $A$ and characterization of its mitochondrial localization targeting signal. J Virol 2004, 78:6498-6508.

73. Schwer B, Ren S, Pietschmann T, Kartenbeck J, Kaehlcke K, Bartenschlager R, Yen TSB, Ott M: Targeting of Hepatitis $\mathbf{C}$ virus core protein to mitochondria through a novel C-terminal localization motif. J Virol 2004, 78:7958-7968.

74. Valentin C, Dunoyer P, Vetter G, Schalk C, Dietrich A, Bouzoubaa S: Molecular basis for mitochondrial localization of viral particles during Beet Necrosis Yellow Vein virus infection. J Virol 2005, 79:999|-10002.

75. Mezéth K, Nylund S, Hendriksen H, Patel S, Nerland AH, Szilvay AM: RNA-dependent RNA polymerase from Atlantic Halibut Nodavirus contains two signals for localization to the mitochondria. Virus Res 2007, I30:43-52.

76. Zhao J, Onduka T, Kinoshita JY, Honsho M, Kinoshita T, Shimazaki KI, Ito A: Dual subcellular distribution of cytochrome $b_{5}$ in plant, cauliflower, cells. J Biochem 2003, I33: I | 5- I 2 I.

77. Henderson MP, Hwang YT, Dyer JM, Mullen RT, Andrew DW: The C-terminus of cytochrome $b_{5}$ confers endoplasmic reticulum specificity by preventing spontaneous insertion into membranes. Biochem / 2007, 40 I:701-709.

78. Maggio C, Barbante B, Ferro F, Frigerio L, Pedrazzini E: Intracellular sorting of the tail-anchored protein cytochrome $b_{5}$ in plants: a comparative study using different isoforms from rabbit and Arabidopsis. J Exp Bot 2007, 58:1365-1379.

79. Du P, Li Y: Prediction of protein submitochondria locations by hybridizing pseudo-amino acid composition with various physicochemical features of segmented sequence. BMC Bioinformatics 2006, 7:518.

80. Habib SJ, Neupert W, Rapaport D: Analysis and prediction of mitochondrial targeting signals. Methods Cell Biol 2007, 80:76|-78|

8I. Heazlewood JL, Millar AH: Arabidopsis mitochondrial proteomics. Methods Mol Biol 2007, 372:559-57I.

82. Heazlewood JL, Tonti-Filippini JS, Gout AM, Day DA, Whelan J, Millar $\mathrm{AH}$ : Experimental analysis of the Arabidopsis mitochondrial proteome highlights signaling and regulatory components, provides assessment of targeting prediction programs, and indicates plant-specific mitochondrial proteins. Plant Cell 2004, 16:24I-256.

83. Dunkley TPJ, Hester S, Shadforth IP, Runions J, Weimar T, Hanton SL, Griffin JL, Bessant C, Brandizzi F, Hawes C, Watson RB, Dupree P, Lilley KS: Mapping the Arabidopsis organelle proteome. Proc Natl Acad Sci USA 2006, I 03:65 I 8-6523.

84. Sambrook J, Fitsch EF, Maniatis T: Molecular cloning: a laboratory manual. In Cold Spring Harbor Cold Spring Harbor Press; 1989.

85. Restrepo MA, Freed DD, Carrington JC: Nuclear transport of plant potyviral proteins. Plant Cell 1990, 2:987-998.

86. Scholtof HB: Rapid delivery of foreign genes into plants by direct rub-innoculation with intact plasmid DNA of a tomato bushy stunt virus gene vector. J Virol 1999, 73:7823-7829.

87. Hu CD, Kerppola TK: Simultaneous visualization of multiple protein interactions in living cells using multicolor fluorescence complementation analysis. Nat Biotechnol 2003 21:539-545.

88. Chiu W, Niwa Y, Zeng W, Hirano T, Kobayashi H, Sheen J: Engineered GFP as a vital reporter in plants. Curr Biol 1996 6:325-330.

89. Shockey JM, Gidda SK, Chapital DC, Kuan JC, Dhanoa PK, Bland JM, Rothstein SJ, Mullen RT, Dyer JM: Tung tree DGATI and DGAT2 
have nonredundant functions in triacylglycerol biosynthesis and are localized to different subdomains of the endoplasmic reticulum. Plant Cell 2006, 18:2294-23 I3.

90. Chuong S, Park NII, Freeman M, Mullen RT, Muench D: The peroxisomal multifunctional protein interacts with cortical microtubules in plant cells. BMC Cell Biol 2005, 6:40-53.

91. Trelease RN, Lee MS, Banjoko A, Bunkelmann J: C-terminal polypeptides are necessary and sufficient for in-vivo targeting of transiently-expressed proteins to peroxisomes in suspension-cultured cells. Protoplasma 1996, 195:156-167.

92. Kunce CM, Trelease RN, Turley RB: Purification and biosynthesis of cottonseed (Gossypium hirsutum L.) catalase. Biochem J 1988, 25 I: | 147-155.

93. Luethy MH, Gemel J, Johnston ML, Mooney BP, Mierynk JA, Randall DD: Developmental expression of the mitochondrial pyruvate dehydrogenease complex in pea (Pisum sativum) seedlings. Physiol Plant 200 I, I I 2:559-566.

94. Bhat RA, Lahaye $T$, Panstruga R: The visible touch: in planta visualization of protein-protein interactions by fluorophorebased methods. Plant Methods 2006:2-12

95. Lalonde S, Ehrhardt DW, Loqué D, Chen J, Rhee SY, Frommer WB: Molecular and cellular approaches for the detection of protein-protein interactions: latest techniques and current limitations. Plant J 2008, 53:610-635.

96. Spurr AR: A low-viscosity epoxy resin embedding medium for electron microscopy. J Ultrastruct Res 1969, 26:3 I-43.

97. Venable JH, Coggeshall R: Simplified lead citrate stain for use in electron microscopy. J Cell Biol 1965, 25:407-408.

98. Tartakoff A, Vassalli P: Lectin-binding sites as markers of Golgi subcompartments: Proximal to distal maturation of oligosaccharides. J Cell Biol 1983, 97: | 243-। 248.

99. Chuong SDX, Mullen R, Muench DG: Identification of a rice RNAand MT-binding protein as the multifunctional protein (MFP), a peroxisomal enzyme involved in the $\beta$-oxidation of fatty acids. J Biol Chem 2002, 277:2419-2429.
Publish with Bio Med Central and every scientist can read your work free of charge

"BioMed Central will be the most significant development for disseminating the results of biomedical research in our lifetime. "

Sir Paul Nurse, Cancer Research UK

Your research papers will be:

- available free of charge to the entire biomedical community

- peer reviewed and published immediately upon acceptance

- cited in PubMed and archived on PubMed Central

- yours - you keep the copyright
BioMedcentral 